\title{
The Investigation of the Optimization Scheme of the Low-cycle Fatigue Cropping Based on the Acoustic Emission Technique
}

\author{
Yujian Ren ( $\sim 857280283 @ q q . c o m$ ) \\ Xi'an Jiaotong University \\ Jingxiang $\mathrm{Li}$ \\ Xi'an Jiaotong University \\ Yuanzhe Dong \\ Xi'an Jiaotong University \\ Dong Jin \\ Xi'an Jiaotong University \\ Shengdun Zhao \\ Xi'an Jiaotong University
}

\section{Research Article}

Keywords: low-cycle fatigue cropping, ring-down counts, kurtosis, section quality, optimal control method

Posted Date: May 13th, 2021

DOl: https://doi.org/10.21203/rs.3.rs-509322/v1

License: (9) (1) This work is licensed under a Creative Commons Attribution 4.0 International License. Read Full License

Version of Record: A version of this preprint was published at Archives of Civil and Mechanical Engineering on February 7th, 2022. See the published version at https://doi.org/10.1007/s43452-02100335-y. 
1 The investigation of the optimization scheme of the low-cycle

2 fatigue cropping based on the acoustic emission technique

3

4 Yujian Ren, Jingxiang Li, Yuanzhe Dong, Dong Jin, Sheng dun Zhao

6 School of Mechanical Engineering, Xi'an Jiaotong University, No.28,

Xianning West Road, Xi’an, Shaanxi 710049, China

8

857280283@qq.com,jxli.xjtu@xjtu.edu.cn,

sdzhao@mail.xjtu.edu.cn 


\begin{abstract}
High efficiency and good section quality are two main objectives of metal bar cropping. A suitable control method can help to achieve both goals. An investigation of the control method of low-cycle fatigue cropping (LCFC) based on the acoustic emission (AE) technique has been proposed in this study. Ring-down counts and kurtosis are used to monitor the whole process of LCFC. The results showed that kurtosis is more suitable for monitoring the LCFC process and as a critical parameter to optimize the control method than ring-down counts in the noisy factory environment.

Moreover, three types of materials are studied in this experiment; by combine with the AE results, macroscopic images and microscopic images of sections, characteristics of various LCFC stages are obtained. The results also indicated reduce the area of the transient fracture zone is the key to improve the section quality. Reducing the load frequency before the unstable crack propagation stage will beneficial to realize the goals. Based on the evaluation of kurtosis, an optimized control method is presented, and two control parameters: transient time $\mathrm{T}$ and the critical value of the slope of kurtosis $\mathrm{C}$ are determined. For $16 \mathrm{Mn}, 1045$ and $\mathrm{Al} 6061$, the $\mathrm{T}$ is $5 \mathrm{~s}, 10 \mathrm{~s}$, and $1 \mathrm{~s}$, respectively. For $16 \mathrm{Mn}, 1045$, and $\mathrm{Al} 6061$, the $\mathrm{C}$ is 100,300 , and 0 , respectively. Two parameters, $\mathrm{h}$ and $\mathrm{S}$, are used to evaluate the section quality and four control strategies are compared. The results indicate the optimal control methods can improve the section quality effectively. The influence trend of reducing loading frequency is investigated by further comparison. It can be seen as the frequency decreases, the efficiency of the section quality improving decreases. In order to realize the optimal results, different control strategies are adopted for different materials. Strategy 1 (high frequency is $20 \mathrm{~Hz}$, high frequency thought the whole process), strategy 2 (high frequency is $20 \mathrm{~Hz}$, low frequency is $8.33 \mathrm{~Hz}$ ), and strategy 3 (high frequency is $20 \mathrm{~Hz}$, low frequency is $6.67 \mathrm{~Hz}$ ) is suitable for $\mathrm{Al} 6061,1045$, and $16 \mathrm{Mn}$, respectively.
\end{abstract}

Key words: low-cycle fatigue cropping, ring-down counts, kurtosis, section quality, optimal control method 


\section{$43 \quad$ Highlights}

44 - An optimized low-cycle fatigue cropping control method based on the acoustic technique is proposed to improve the section quality and ensure production efficiency.

- A new low-cycle fatigue cropping system is established to investigate the effects of the optimize control method.

- The kurtosis is more suitable to as a critical parameter of the optimize control method in a noisy factory environment.

- The optimized control method is proved to improve the section quality effectively and ensure production efficiency at the same time.

52 - For 16Mn, 1045, Al 6061 metal bars, the optimal control scheme is determined respectively. 


\section{Introduction}

The cropping of metal is the first step of industrial production. There are some common deficiencies in traditional cropping methods such as the high active load, low energy efficiency and a large number of sectional defects exits. Hua et al. [1] proposed the low-cycle fatigue cropping (LCFC) method, which could solve the above problem. In this method, a metal bar is applied on the cyclic loading, and a V-shaped groove is prefabricated on the surface of the bar to produce the stress concentration effect. Dong et al. [2] investigate the evolution of the LCFC by using SEM, find cracks initiate at the root of V-shaped groove, and propagate throughout the V-shaped groove until fracture. Wang et al. [3] used the analytical, numerical and experimental methods to investigate the kinetic properties of the new approach; the results showed this new type of cropping method is an advanced green manufacturing method, which overcomes the problem of high load in the traditional cropping methods.

To eliminate the defect of the section, numerous research efforts have been devoted .Some studies focus on the processing parameters of the LCFC system. Zhong et al. [4] investigated the effect of the interstice and the notch-sensitivity in the LCFC process, and pointed out the ductile damage initiation was affected by the interstice $\left(C_{1}\right)$ between the bar and the clamping device, and the interstice $\left(C_{2}\right)$ between the bar and crevice significantly; for metal bars with a diameter of $40 \mathrm{~mm}$, the optimal geometric parameters are $C_{1}=0.1 \mathrm{~mm}$, and $\mathrm{C}_{2}=0.1 \mathrm{~mm}$. By investigating the effect of the bottom corner of the groove on the metal bar surface and the impact of clamping position, Zhang et al [5]found the crack initiate at the MES( maximum equivalent stress) gradient point and obtained the proper clamping position: the rate of distance $L_{1}$ (distance between groove and clamping position) to the bar diameter is 0.3 , and the rate of distance $L_{2}$ (distance between groove and cropping die) to the bar diameter is 0.25 . Besides, Zhao et al [6]established a FEM model to investigate the relationship between the temperature the stress, and found that the cropping time was reduced by a prefabricating crack at the notch bottom with the heat stress. Other researchers design different control curves during the cropping process. Zhao et al [7] designed two control curves, and found that constantly increasing displacement and reducing striking frequency can obtain stable crack propagation and fracture. Hua et al [8] designed five types of control curves to study the influence of loading mode on section quality. The results showed that the linear decrement control curve had a good performance in producing high quality section. However, the above control strategies are based on experience rather than the characteristics of the crack growth process, which leads to the efficiency and the section quality have not been improved to the maximum extent. Therefore, the primary work of this research is to study the characteristics of low-cycle fatigue cropping process and find optimal control methods for LCFC at different stages.

A suitable monitoring method is necessary to investigate the characteristics and provide a basis for optimization strategy. Carolan et al. [9] pointed out $\mathrm{AE}$ technique is effective to measure the changing process of metal materials with non-contact, and can get change rule of fatigue process. FANG and BERKOVITS [10] carried out fatigue tests on Incoloy 901 material specimens by using the AE method. He found AE signal generates when plastic deformation, crack initiation and crack propagation occur, and characteristics of the fatigue process can be obtained via analysis of the AE signal. One analysis method is parameter analysis which is based on the properties of the 
signal. Many parameters such as amplitude, ring-down counts, kurtosis and energy can be used to analyze fatigue crack propagation process. Roberts and Talebzadeh [11] set up an AE system to monitor the steel and welded steel fatigue propagation, and obtained the reasonable relevance between the rates of $\mathrm{AE}$ counts and the rates of crack propagation. Elforjani and Mba [12] used energy, counts, amplitude and ASL (the average value of the amplitude of AE signal) in a shaft run to failure tests, and prove these parameters detect the crack and damage in low-speed shaft are effective. Han et al. [13] established the relationship among the counts, cycles and crack length by studying the characteristics of fatigue crack propagation stage in the base metal and wield of Q345 steel. According to the results, Han divided the fracture process into 3 stages: crack initiation stage, crack growth stage and final fracture. Yu et al. [14] found the absolute energy could be used to warn the unstable growth because of the absolute energy less depended on the threshold value. Aggelis et al [15] come up with a new parameter RA value (ratio of rise time to amplitude) and used it do a damage assessment for metal plates. He found the RA value could indicate the predominant cracking model from tensile to shear. Chai et al. [16] came up with a new parameter: AE entropy to investigate the fatigue process of $316 \mathrm{LN}$ stainless steel, and found it can be used to assess the damage of fatigue process under high noise loading environment accurately.

The above excellent studies are focused on the high-cycle fatigue process; few studies focus on the LCFC process. It is necessary to determine AE parameters for monitoring LCFC process. Li et al. [17] mainly concentrated on the AE detection of low-cycle fatigue, and found amplitude, ring-down counts and kurtosis are able to as monitoring parameters to study the LCFC process. Ren et al. [18] studied the effect of notch eccentric ratio during process of the LCFC by using counts and kurtosis, and found these parameters could offer valuable information to get the affection of the factors during the LCFC process. Considering the amplitude represents the signal's intensity, and it couldn't characterize the frequency of plastic and fracture events. Hence, ring-down counts and kurtosis are selected to monitor the whole process in this study. Two parameters are compared to choose one as the critical parameter to optimize the control strategy. Furthermore, to observe the microscopic evolution of fatigue crack propagation and evaluate the section quality before and after optimization, a scanning electron microscope (SEM) and an optical microscope (OM) system are used.

\section{Principle of LCFC method}

The schematic diagram of the principle of the LCFC is shown in Fig.1. The fixed sleeve supports the left end of the bar, and the cropping die shove on the right end of the bar. Due to the eccentricity e between the axis $\mathrm{O}_{1}-\mathrm{O}_{1}$ and the axis $\mathrm{O}_{2}-\mathrm{O}_{2}$, the Eccentric sleeve die and spindle applied cyclic loading on the bar's surface. Due to the prefabricated V-shaped groove, which generates stress concentration, the fatigue cracks occurred at the tip of notch and propagated until the metal bar fracture. 


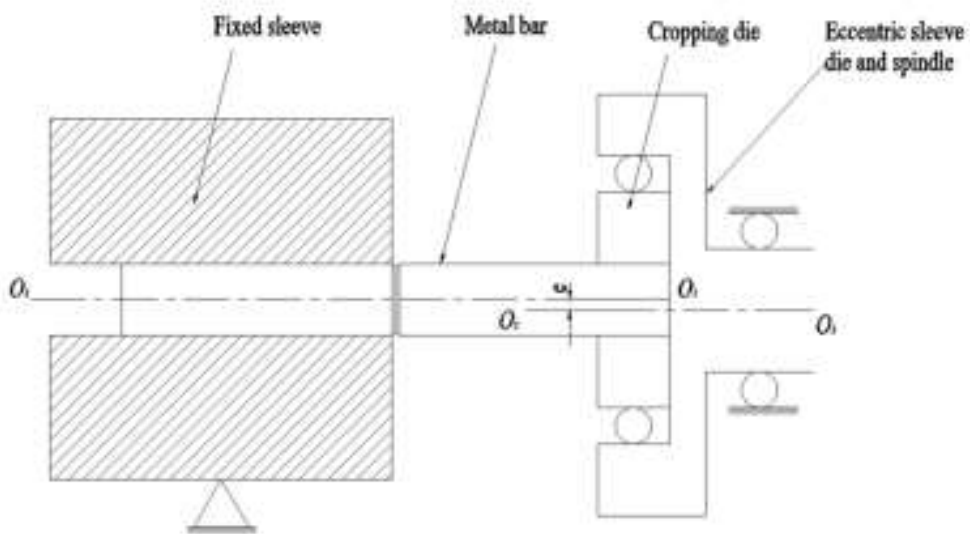

Figure 1. The schematic diagram of the working principle of LCFC.

\section{Materials and Methods}

The new type of LCFC system includes three parts: LCFC machine, control system and monitoring system. A brief description of the composition and the principle of these three parts are given in the following content.

\subsection{The new type of LCFC machine and experiment materials}

The new LCFC machine is shown in Figure 2. The left end of the metal bar is connected with the sleeve, which is fixed in the three jaw chuck 1 . The servo motor 1 drives the ball screw to rotate, and the three jaw chuck 1 moves along the X-axis, which applying a $3 \mathrm{~mm}$ displacement load to the metal bar. The right side of the metal bar is fixed at the prefabricated groove in the three jaw chuck 2, and it is driven by servo motor 2 to rotate along the Y-axis which applying a cyclic displacement load to the metal bar. The experimental device is shown in Figure 2(b); in this machine, servo motor power is $2.6 \mathrm{~kW}$.

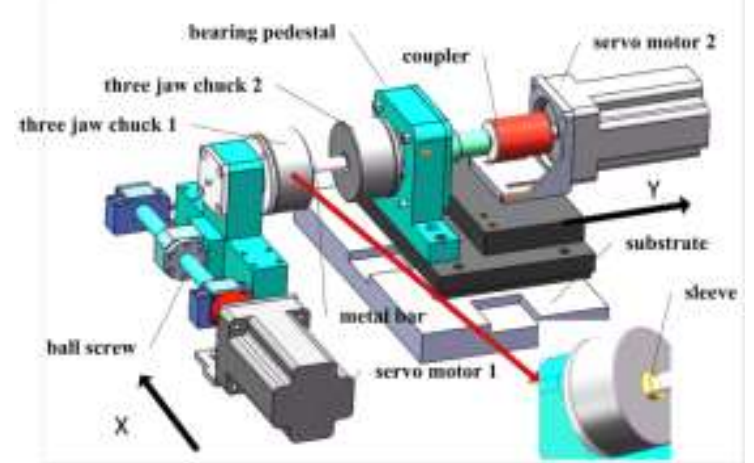

(a)

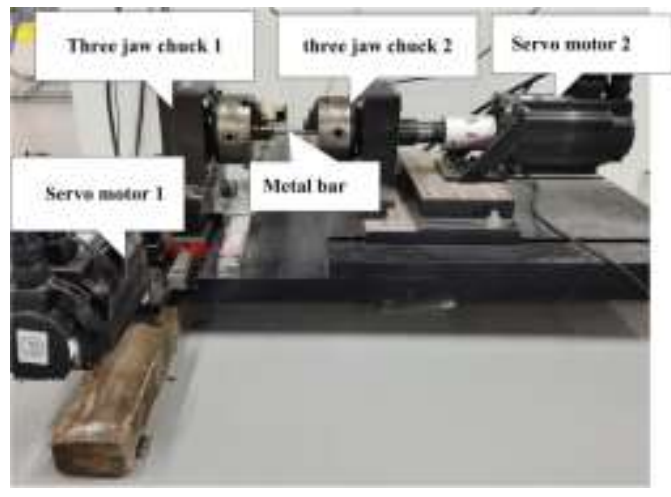

(b)

Figure 2 The new types of LCFC machine. (a) Structural schematic diagram (b) Experimental device

Three metal materials are presented in this experiment: $1045,16 \mathrm{Mn}$ and $\mathrm{Al} 6061$. The materials properties are presented in Table 1. The geometric parameters of metal bar are presented in Fig 3 (a). The length of the metal bar $\mathrm{L}_{1}$ is $75 \mathrm{~mm}$, and the diameter of metal bar $\mathrm{D}$ is $12 \mathrm{~mm}$. The width of the $\mathrm{V}$-shaped notch $\mathrm{C}$ is $0.2 \mathrm{~mm}$, and the angle of the V-shaped notch $\emptyset$ is $90^{\circ}$. The depth of $\mathrm{V}$-shaped notch $\mathrm{d}$ is $1 \mathrm{~mm}$, and the corner radius of the $\mathrm{V}$-shaped 


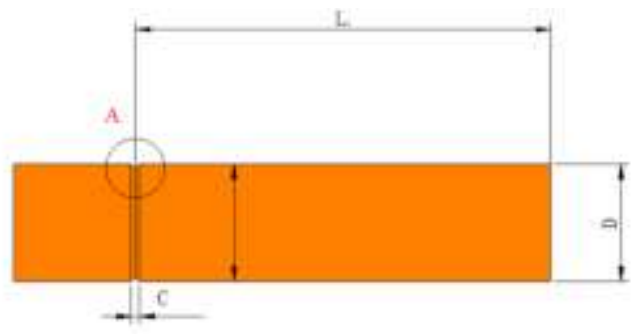

A

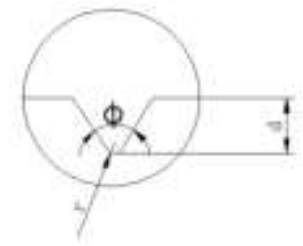

(a)

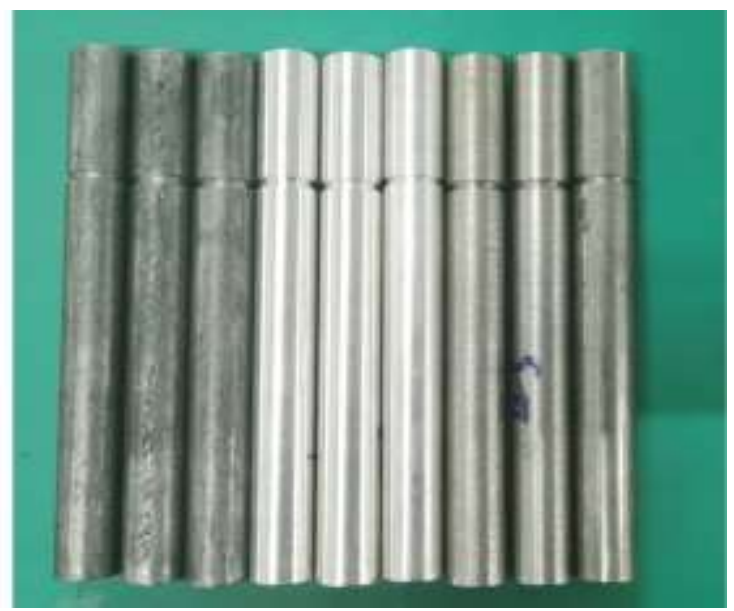

(b)

Figure 3. The geometric paramters and the images of the metal bar.(a) The diagram of geometrical structure (b) The images of three types metal bar:from left to right are 16Mn, $\mathrm{Al} 6061$ and 1045.

Table 1 Mechanical properties of the specimens.

\begin{tabular}{l|l|l|l}
\hline Parameters & $16 \mathrm{Mn}$ & 1045 & Al 6061 \\
\hline $\begin{array}{l}\text { Elastic Modulus }(E) \\
\text { Poisson's ration }(\mu)\end{array}$ & $206 \mathrm{GPa}$ & $210 \mathrm{GPa}$ & $71 \mathrm{GPa}$ \\
Yield strength $\left(\sigma_{s}\right)$ & 0.3 & 0.3 & 0.33 \\
& $345 \mathrm{MPa}$ & $355 \mathrm{MPa}$ & $55.2 \mathrm{MPa}$ \\
Tensile strength $\left(\sigma_{b}\right)$ & $470 \sim 630 \mathrm{MPa}$ & $600 \mathrm{MPa}$ & $124 \mathrm{MPa}$ \\
Threshold stress intensity & $183.41 \mathrm{MPa} \times \mathrm{mm}^{1 / 2}$ & $252.98 \mathrm{MPa} \times \mathrm{mm}^{1 / 2}$ & $3.47 \mathrm{MPa}^{\times} \mathrm{mm}^{1 / 2}$ \\
factor $\left(\Delta K_{\text {th }}\right)$ & & & \\
Fracture toughness $\left(K_{\mathrm{IC}}\right)$ & $443.64 \mathrm{MPa} \times \mathrm{mm}^{1 / 2}$ & $1890 \sim 1950 \mathrm{MP} \times \mathrm{mm}^{1 / 2}$ & $8.32 \sim 13.2 \mathrm{MP}^{\prime} \mathrm{mm}^{1 / 2}$ \\
\hline
\end{tabular}

\subsection{The control system for LCFC}

The diagram of the control system is shown in Figure 4(a). The computer sends pulse commands to the s7-200 programmable logic controller (PLC). Two servo motors are controlled by PLC, and provide a rotating load and eccentric displacement, respectively. The PLC program logic control schemes for servo motor 1 and servo motor 2 are shown in Table 2 and Table 3, respectively. The rotation control program realizes high and low speed conversion, and the flow chart is shown in Figure 4(b). The eccentric displacement control program realizes the displacement loading and unloading, and the flow chart is shown in Figure 4(c). In this study, high frequency is $20 \mathrm{~Hz}$ $(\omega=1200 \mathrm{r} / \mathrm{min})$, and low frequency is $10 \mathrm{~Hz}(\omega=600 \mathrm{r} / \mathrm{min}), 8.33 \mathrm{~Hz}(500 \mathrm{r} / \mathrm{min})$ and $6.67 \mathrm{~Hz}$ $(400 \mathrm{r} / \mathrm{min})$. 


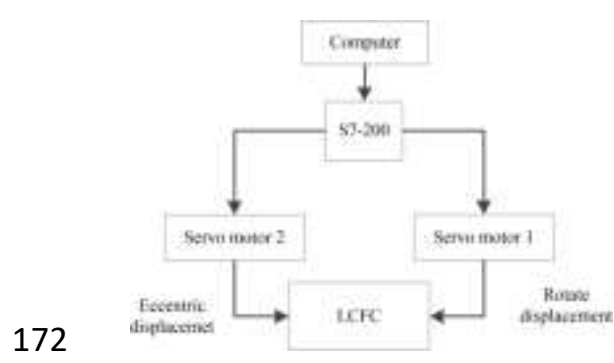

(a)

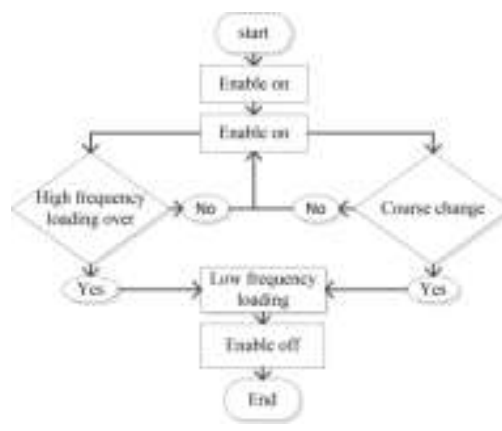

(b)

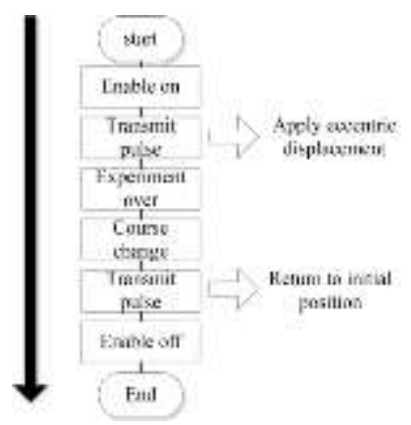

(c)

174 Figure 4 Schematic of the control system. (a) Two servo motors are controlled by s7-200 PLC. (b) Flow chart of rotation control program.

(c) Flow chart of eccentric displacement control program.

Table 2 The PLC program logic control table for servo motor 1.

\begin{tabular}{llllllll}
\hline $\mathrm{I} 0.3$ & $\mathrm{I} 0.4$ & $\mathrm{I} 0.5$ & $\mathrm{I} 0.7$ & $\mathrm{Q} 0.5$ & $\mathrm{Q} 0.6$ & $\mathrm{Q} 0.7$ & State of the motor \\
\hline 1 & $\mathrm{x}$ & $\mathrm{x}$ & 1 & 0 & 0 & 0 & Enable off \\
1 & 0 & $\mathrm{x}$ & 0 & 1 & 0 & 0 & $\omega=0$ \\
0 & $\mathrm{x}$ & $\mathrm{x}$ & $\mathrm{x}$ & 0 & 0 & 0 & Enable off \\
1 & 1 & 0 & 0 & 1 & 1 & 0 & High frequency \\
1 & 1 & 1 & 0 & 1 & 1 & 1 & Low frequency \\
\hline
\end{tabular}

177

Table 3 The PLC program logic control table for servo motor 2.

\begin{tabular}{llllllll}
\hline $\mathrm{I} 0.0$ & $\mathrm{I} 0.1$ & $\mathrm{I} 0.2$ & $\mathrm{I} 0.6$ & $\mathrm{Q} 0.0$ & $\mathrm{Q} 0.2$ & $\mathrm{Q} 0.4$ & State of the motor \\
\hline 0 & $\mathrm{x}$ & $\mathrm{x}$ & $\mathrm{x}$ & $\mathrm{x}$ & 0 & 0 & Enable off \\
1 & 0 & $\mathrm{x}$ & 0 & $\mathrm{x}$ & 0 & 1 & Enable on \\
1 & $\mathrm{x}$ & $\mathrm{x}$ & 1 & $\mathrm{x}$ & 0 & 0 & Enable off \\
1 & 1 & 0 & 0 & pulse & 0 & 1 & Positive rotation \\
1 & 1 & 1 & 0 & pulse & 1 & 1 & Reverse rotation \\
\hline
\end{tabular}

\section{$178 \quad 3.3$ The monitoring system for LCFC}

179 As shown in Figure 5, the monitoring system includes a computer, a sensor (AE sensor) and an acquisition card (PCI-1714). The AE sensor model is Nano30 which peak frequency is $293 \mathrm{kHz}$, and the bandwidth is $125-750 \mathrm{kHz}$ (Physical Acoustics Corporation, USA), and attached to the

182 sleeve with a magnetic seat. The ultrasonic complants are coated on the surface of sensor to ensure the intensity of the signal. During the experiment, signal are obtained by AE sensor, amplified by an operational amplifier, and stored in the computer through the acquisition card which sampling rate can attain $30 \mathrm{M} / \mathrm{s}$. In this experiment, the sampling frequency is set as $2 \mathrm{M} \mathrm{Hz}$. To preprocess the $\mathrm{AE}$ signal, the frequency range of the bandpass filter is set as 25 to $800 \mathrm{kHz}$. 

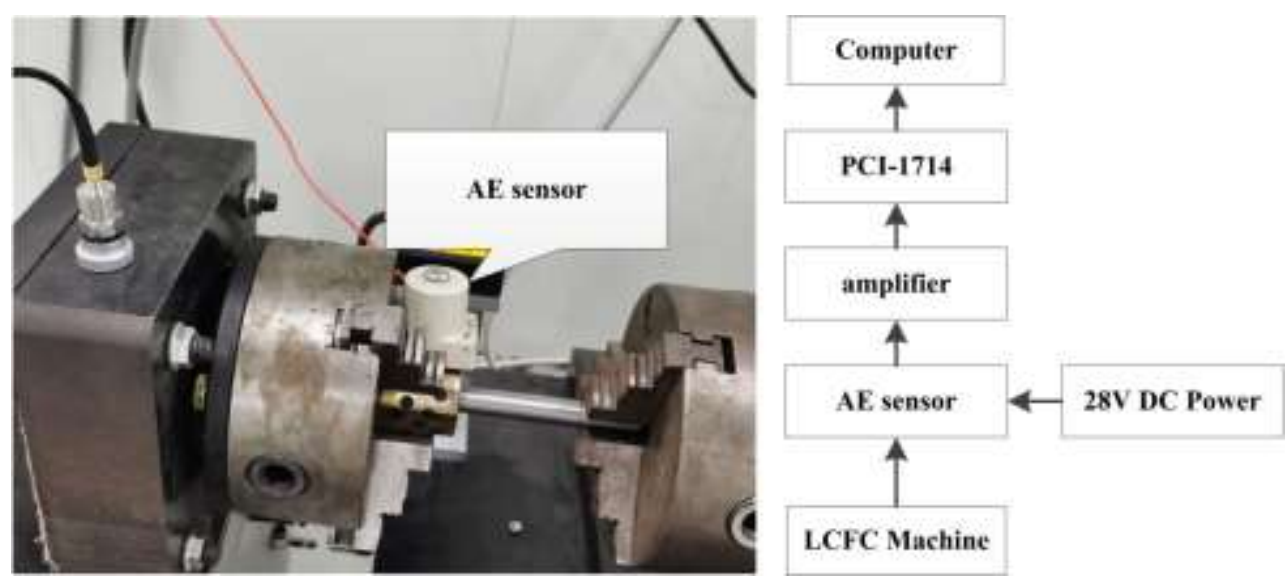

Figure 5 The diagram of the monitoring system.

189

\section{Results and discussion}

\subsection{AE results}

Ring-down counts represent the number of events per unit time, and are suitable to describe the crack propagation stage. Kurtosis representing an outlier prone distribution which related to the fourth standardized moment about the mean of the data [19]; it can be used to characterize the sudden variation of material and describe the abrupt change between various stages. The ring-down counts during the LCFC process are used to compare with AE kurtosis to select a more suitable parameter as the critical parameter to optimize the control strategy.

Figure 6(a), (c), (e) show the variation in ring-down counts vs. loading time for different kinds of metal bar materials. It can be seen, a sudden rise of ring-down counts ranged from 0 to 8000, 8453 and 3973 for 16Mn, 1045 and $\mathrm{Al} 6061$ at the beginning of the LCFC process, respectively. This sudden increase is mainly related to the crack initiation stage. Cracks initiate at the adjacent region of the V-shaped groove tip and enhance the strength of the AE signal. Subsequently, as shown in Figure 5(a) (c), the ring-down counts maintain a stable range, for $16 \mathrm{Mn}$, from $1.3 \mathrm{~s}$ to $9.7 \mathrm{~s}$, the values of ring-down counts remain steady between 7000 to 10000 ; for 1045 , from $7.5 \mathrm{~s}$ to $16.7 \mathrm{~s}$, the value of ring-down counts remain steady between 7500 to 8500 . This stage is mainly related to crack propagation. In this stage, the size of the plastic zone increased, and the intensity of the AE signal exceeds the threshold value. According to the previous studies, there is a good linear relationship between $\lg (d a / d N)$ and $\lg \Delta K$. with the increase of the $\Delta K$, the crack growth rate $(d a / d N)$ increased stably. However, Fig. 6(e) shows a different pattern of change that there is no stable stage of ring-down counts. This might due to the $K_{I C}$ of Al 6061 is small, $\Delta K$ has reached $K_{I C}$ before the crack enters the stable growth stage. At the last stage, the value of the ring-down counts decreases rapidly from 8320 to 0,7860 to 0 and 3885 to 0 for $16 \mathrm{Mn}, 1045$ and $\mathrm{Al} 6061$, respectively. At this time, $\Delta K=K_{I C}$ the crack growth rate $(d a / d N)$ reach a high value and the metal bar fracture immediately.

Figure 5(b), (d), (f) shows the variation in ring-down counts vs. loading time for different metal bar materials. As can be seen from the parts of $b, d$, the peak of kurtosis concentrated in two areas. For $16 \mathrm{Mn}$, the first peak of kurtosis emerged from $0.3 \sim 0.7 \mathrm{~s}$; the maximum value of the kurtosis is 
39. The second peak of kurtosis emerged from 9.7 10.5s; the maximum value of the kurtosis is 156. For 1045, the first peak of kurtosis emerged from $3.1 \sim 4.3 \mathrm{~s}$; the maximum value of the kurtosis is 83 . The second peak of kurtosis emerged from $16.7 \sim 18.7 \mathrm{~s}$; the maximum value of the kurtosis is 279. Ruiz-Carcel et al. [20] pointed out the kurtosis representing a distribution of outlier-prone, which can be defined as:

$\beta=\frac{E(\mathrm{x}-\mu)^{4}}{\sigma^{4}}$

Where $\mu$ is the mean of $x, \sigma$ is the standard deviation of $x$ and $E$ represents the expected value of quantity. According to Formula (1), kurtosis indicates the waveform' smoothness, and the peak kurtosis value indicates a dramatic change of the material. The above results showed there are two time points in low cycle blanking in which the signal changes dramatically. These two time points are defined as transition point 1 and transition point 2, respectively. As shown in Figure 5(f), for Al 6061, from 2.2s to 4.4s, the value of kurtosis change dramatically, which showed there is no stable stage from the crack propagation to the fracture. In other words, there is no significant boundary between crack propagation stage and fracture stage for Al 6061. This result consistent with the result of the ring-down counts, and it will be explained by a macroscopic photograph of a section below.

235

236

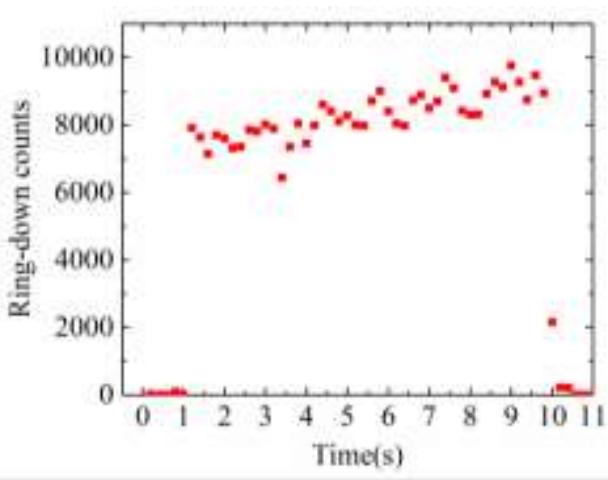

(a)

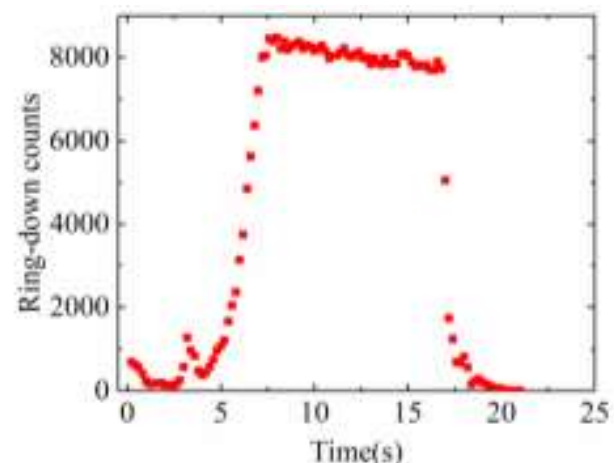

(c)

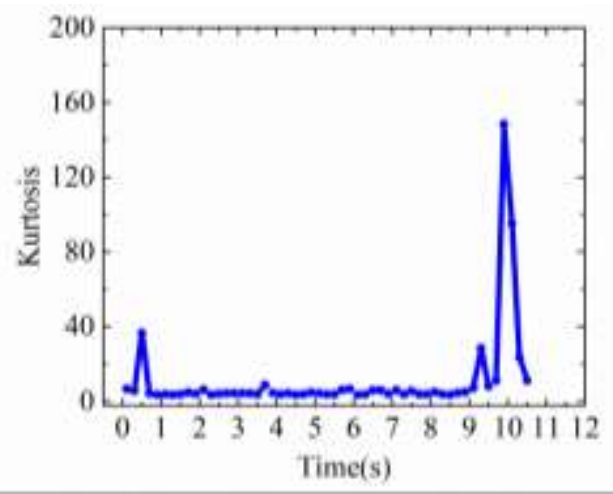

(b)

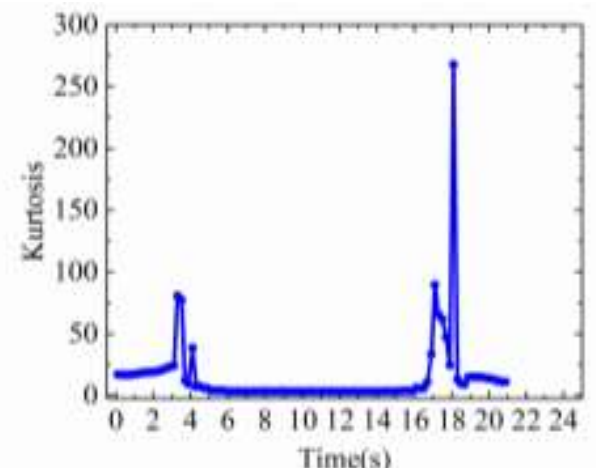

(d) 


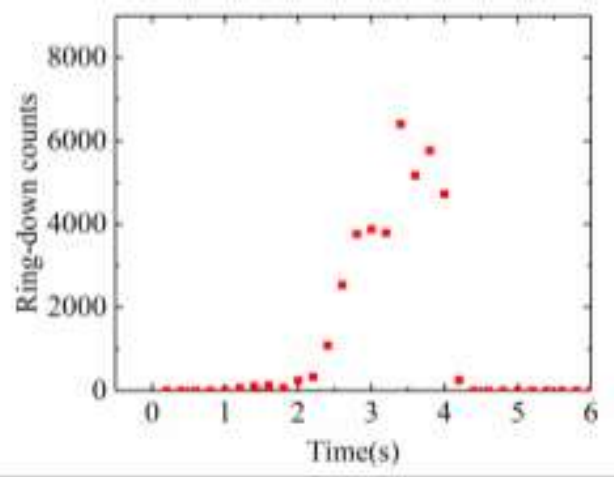

(e)

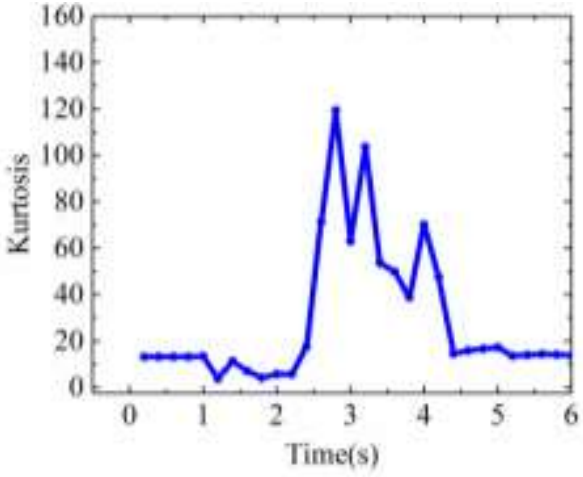

(f)

Figure 6.Ring-down counts vs. time (a, c, e) and kurtosis vs. time (b, d, f) with 16Mn specimens (a b), 1045 specimens (c, d) and Al 6061 (e, f).

It is obvious from the above analyses that the ring-down counts and kurtosis can be used to monitor the whole process of LCFC. However, the above results are built in the relative quiet environment of the lab; the background noise is stable and low. In this experiment, the threshold value of the event is $5.2 \mathrm{~V}$, which is about twice over the background noise to avoid noise signal interference. In actual industrial production, the background noise changes all the time. Hence, which parameter is not affected by the threshold value of event will be more suitable for monitor the process of LCFC and as a critical parameter of the optimization control method. According to the definition of ring-down counts and kurtosis, ring-down counts depend on the threshold value and the kurtosis does not. When the threshold value of the event is change to $0.3 \mathrm{~V}$, as shown in Figure 7(a), ring-down counts start to rise rapidly from $6.7 \mathrm{~s}$ and reach a maximum of 7242 at $14.9 \mathrm{~s}$, and from $11.1 \mathrm{~s}$ to $16.5 \mathrm{~s}$, the values of ring-down counts remain stable between 6540 to 7242. Compare with Figure 6(c) and Figure 7(a), it can be seen the maximum value of the ring-down counts and the duration of the rising and stable phases had changed when the threshold value changed. Compare with Figure 6(d) and Figure 7(b), the variation in kurtosis as a function of fatigue loading time has not been changed. From the above analysis, the kurtosis is more stabilized and suited for monitoring the process of LCFC in a noisy factory environment.

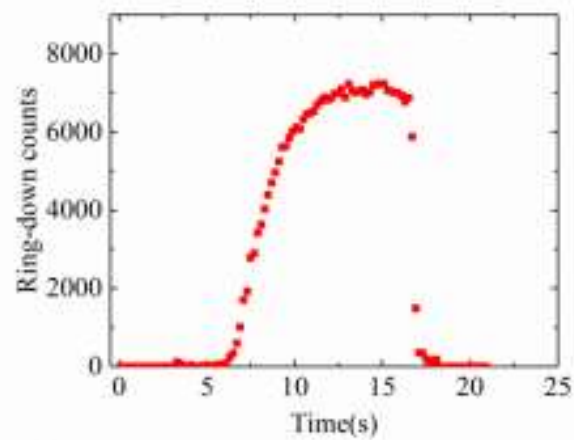

(a)

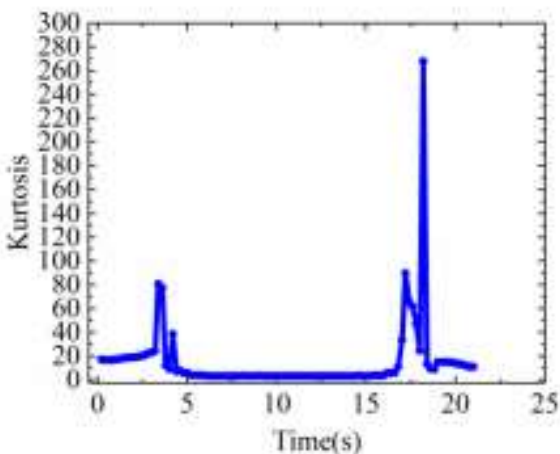

(b)

Figure 7.Ring-down counts vs. time (a) and kurtosis vs. time (b) with 1045 specimens when the threshold value of peak event is 0.3 .

\subsection{Fatigue propagation mechanism}


To obtain a suitable control method based on the characteristics of fatigue propagation, the OM system and SEM are used to investigate the evolution of fatigue propagation. The macroscopic sections of metal bars and microscopic sections of metal bars are shown in Figure 8 and Figure 9, respectively.

As shown in Figure 8(a), (b), for 16Mn and 1045, there are three different zones which related to three stages of fatigue process: crack initiation stage, crack propagation stage and fracture stage. As shown in Figure 8(c), For Al 6061, there are only two different zones. There is no obvious boundary between the crack propagation stage and the fracture stage. The positions marked by red dots in the Figure 8 are scanned by SEM. As shown in Figure 9(a), (d), (g), the microscopic view of crack initiation stage of $16 \mathrm{Mn}, 1045$ and $\mathrm{Al} 6061$ revealed the fatigue striations predominant the zone 1 . At zone I, the materials go through slight plastic deformation near the $\mathrm{V}$-shaped notch and form the fatigue striations. In this stage, the materials crack along the direction of the red arrow which perpendicular to the fatigue band and the crack growth rate $(\mathrm{da} / \mathrm{dN})$ is less than $0.1 \mu \mathrm{m} /$ cycle. The damage accumulates slowly, which leads to the signal strength are less than the threshold value. Hence, the ring-down counts and kurtosis are close to 0 in this stage. Figure 9(b), (e), (h) show the microscopic view of crack propagation stage; it can be seen for 16Mn and 1045 , dimples and fatigue striations are predominant in crack surfaces; for Al 6061, there are almost no fatigue striations. The above results can be used to explain why there is no stable crack growth stage for Al 6061 based on the evolution of microstructure. Compare with the crack initiation stage, the crack growth rate $(d a / d N)$ increased, which leads to the signal strength increase. Moreover, the formations of the dimples also generate intense AE signals. Hence, the value of ring-down counts in the crack propagation stage is much larger which in crack initiation stage. Figure 9(c), (f), (i) display the microscopic image of the center area of the metal bar. Equiaxed dimples predominant the crack surface and the depth of the dimples are larger than which in the crack propagation stage. The above phenomenon shows that the tensile fracture is the primary damage model during the fracture stage. In this stage, metal bars go through unstable crack growth until fracture, large are of transient fracture zone produced and the section quality reduced.

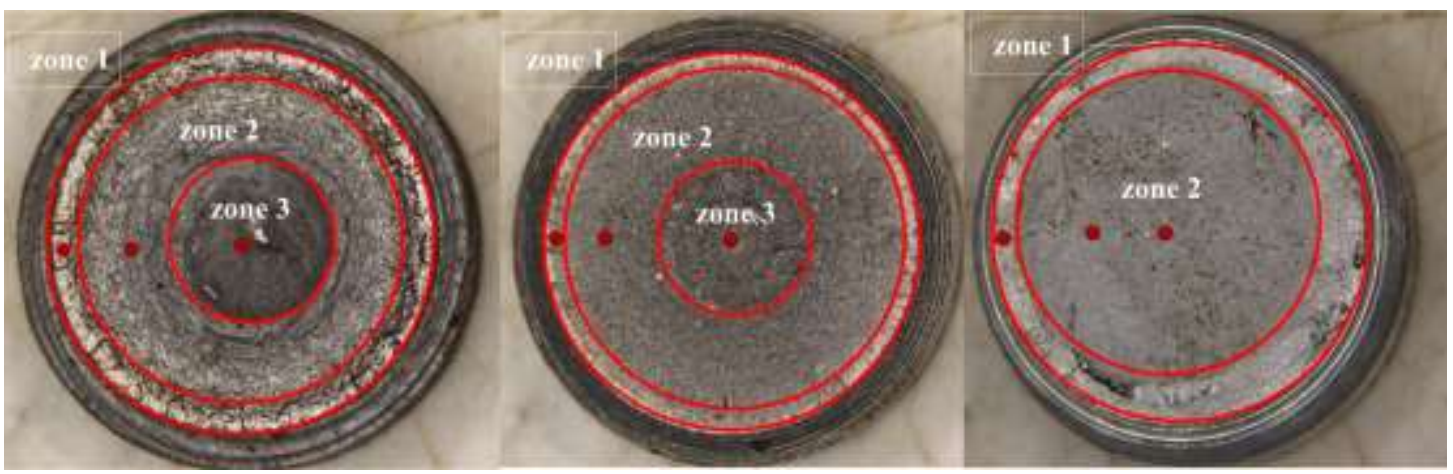

Figure 8.The macroscopic cross-sections of metal bars. (a) 16Mn, (b) 1045, and (c) Al 6061. 


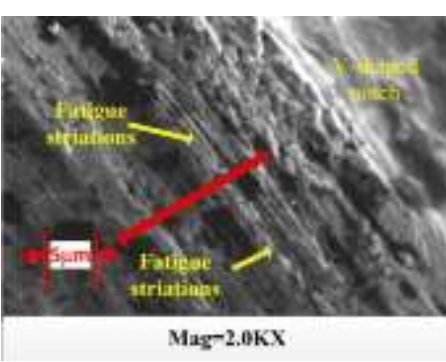

(a)

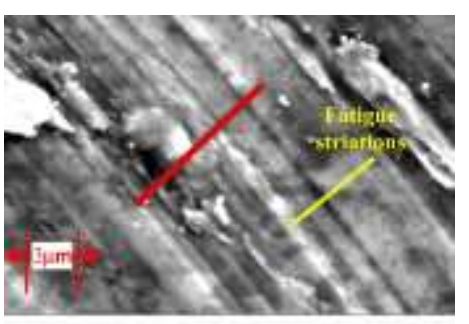

Mag-3.0KX

(d)

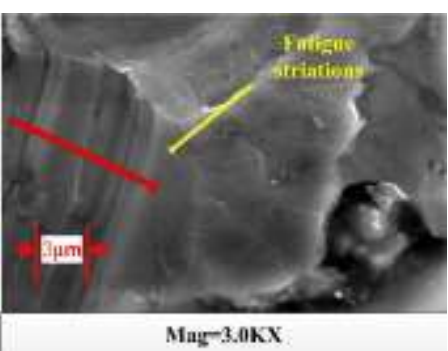

(g)

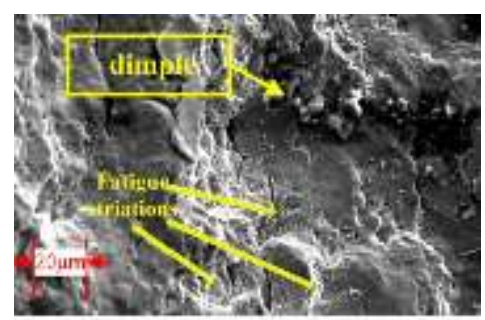

M*g-500X

(b)

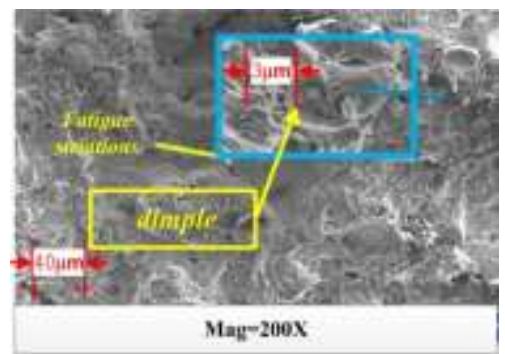

(e)

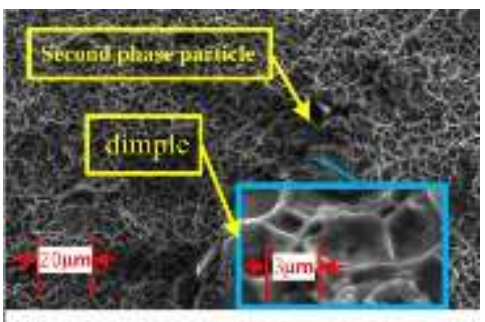

Mag $=200 X$

(h)

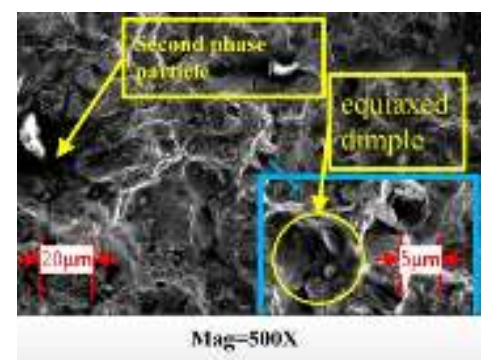

(c)

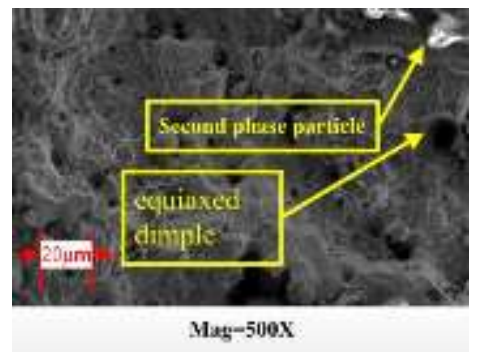

(f)

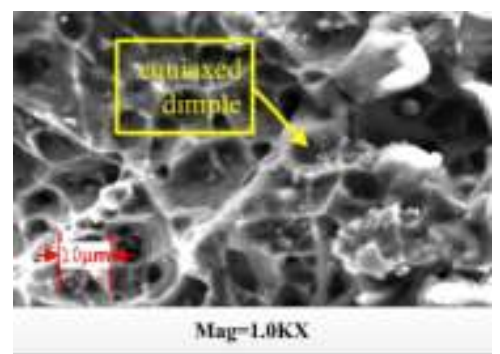

(i)

Figure 9 Different stages of fatigue fracture surface of three types of materials (a) crack initiation area of 16Mn (b) crack propagation area of $16 \mathrm{Mn}(\mathrm{c})$ fracture area of $16 \mathrm{Mn}(\mathrm{d})$ crack initiation area of 1045 (e) crack propagation area of 1045 (f) fracture area of $16 \mathrm{Mn}(\mathrm{g})$ crack initiation area of Al 6061 (h) crack propagation area of Al 6061 (i) fracture area of $\mathrm{Al} 6061$

According to the study of [17], the higher frequency can accelerate the crack growth in the plastic zone and make the cropping efficiency improve, but it will lead to insufficient plastic deformation during the crack propagation, area of transient fracture zone increased and section quality reduced. Combine with the above microscopic evolution of the crack propagation, reduce the load frequency before crack unstable growth stage will reduce the area of transient fracture, which is beneficial to improve the section quality and also ensure the cropping efficiency. The specific control methods will be discussed below.

\subsection{The optimize control method and the assessment of section quality}

According to the analyses of the above sections, the kurtosis is set as the critical parameter which is used to optimize the control method and the best time to reduce the load frequency is before unstable crack propagation. As shown in Figure 10, there is a rise edge before unstable crack propagation stage, which can be set as the control point. It can be seen there are two rise edges during the whole process for $16 \mathrm{Mn}$ and 1045, and only one rise edge for $\mathrm{Al} 6061$. Hence, for 
$16 \mathrm{Mn}$ and 1045 , the time of second rise edge occurred is set as the control point; for $\mathrm{Al} 6061$, the time of first rise edge occurred is set as the control point. To know the accurate time when the rise edge occurred, the derivative of kurtosis with time is calculated, and the slope of kurtosis is obtained. At the control point, for 16Mn, 1045 and Al 6061, the slope of kurtosis is bigger than 100, 300 and 20, respectively. The control method scheme is illustrated in figure 11: firstly, the metal bar is applied under the high frequency load, when the load time is over the $\mathrm{T}$ and the slope of kurtosis is bigger than $\mathrm{C}$, the computer gives commands to PLC to change the state of the servo motor from high frequency to low frequency until the metal bar fracture. $\mathrm{T}$ is a transient time that is used to avoid the interference of the first rise edge, and for $16 \mathrm{Mn}, 1045$ and $\mathrm{Al} 6061$ the $\mathrm{T}$ is $5 \mathrm{~s}$, $10 \mathrm{~s}$, and $1 \mathrm{~s}$, respectively. $\mathrm{C}$ is the critical value of slope of kurtosis which is used to indicate the presence of control points, and for 16Mn, 1045 and $\mathrm{Al} 6061$ the $\mathrm{C}$ is 100, 300, and 0, respectively. As shown in Table 4, the high frequency is set as $20 \mathrm{~Hz}$, and three load frequencies, i.e., $8.33 \mathrm{~Hz}$, $6.67 \mathrm{~Hz}, 5 \mathrm{~Hz}$, are set in the low frequency region to compare the influence of different frequency loads.

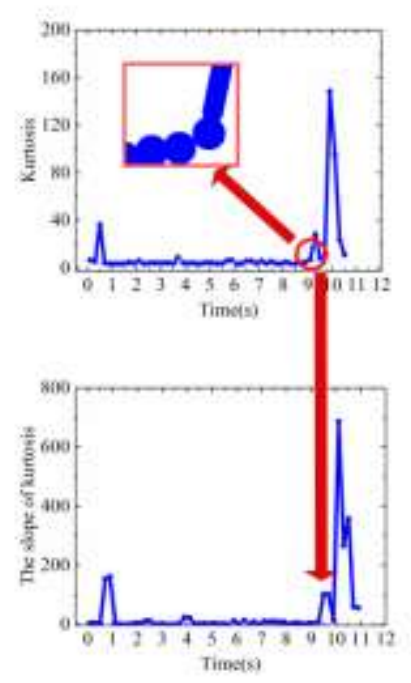

(a)

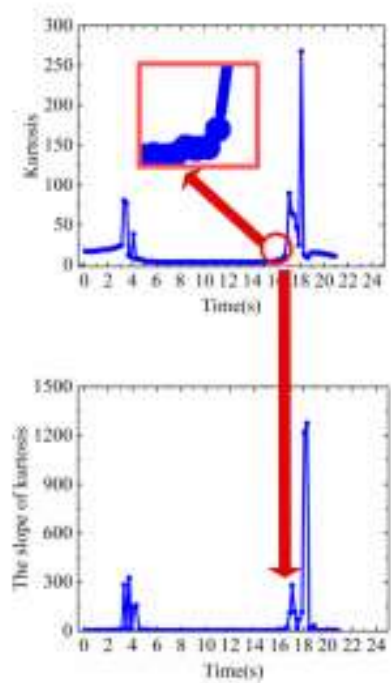

(b)

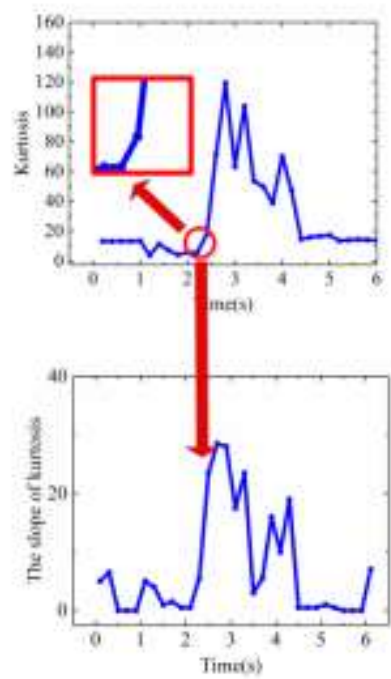

(c)

Figure 10. The rise edge of kurtosis and the slope of kurtosis of metal bars (a) 16Mn (b) 1045 (c) Al 6061

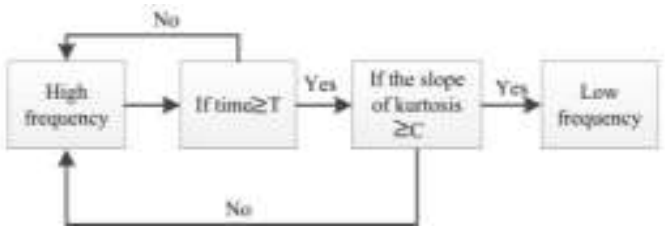

Figure 11. The logic of optimize control method

Table 4 Four control strategies.

\begin{tabular}{l|l|l|l|l}
\hline & Strategy 1 & Strategy 2 & Strategy 3 & Strategy 4 \\
\hline High frequency region & $20 \mathrm{~Hz}$ & $20 \mathrm{~Hz}$ & $20 \mathrm{~Hz}$ & $20 \mathrm{~Hz}$ \\
\hline Low frequency region & & $8.33 \mathrm{~Hz}$ & $6.67 \mathrm{~Hz}$ & $5 \mathrm{~Hz}$ \\
\hline
\end{tabular}

To compare the section quality before and after optimization, as shown in Figure 12, two 
evaluation indexs are presented, in which $\mathrm{h}$ represents the height between the highest point and the lowest point on the section, and S represents the area of the fracture zone. The OM system, OLYMPUS DSX1000, is used to observe the roughness of the section. The $\times 42$ objective is selected and 3D information of the section surface is obtained through automatic image splicing.

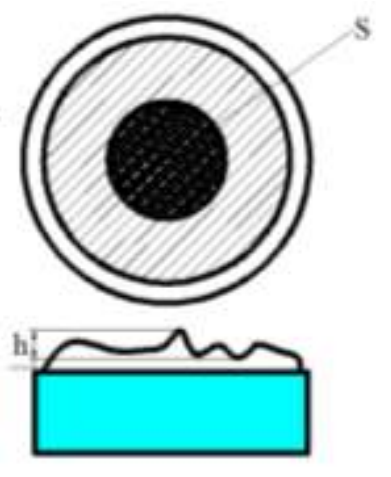

Figure 12. The diagram of two section quality evaluation indexes.

The section information of metal bars with different control strategies are presented in Figure 13. It can be seen from Figure 13(a) that the roughness measuring part can be used to obtain the height (h). Each sample is measured 10 times, and the average height value of different materials under four control strategies are shown in Figure 13(b),(c) and (d). When the frequency change at the control point, $\mathrm{h}$ reduces obviously. For $16 \mathrm{Mn}$, the height value drops from $1836 \mu \mathrm{m}$ to $1182 \mu \mathrm{m}$ by $35.62 \%$; for 1045 , the height value goes from $721.3 \mu \mathrm{m}$ to $368.2 \mu \mathrm{m}$ by $48.95 \%$; and for $\mathrm{Al}$ 6061 , the height value goes from $52.35 \mu \mathrm{m}$ to $35.21 \mu \mathrm{m}$ by $32.74 \%$. Furthermore, the area of the fracture zone reduces significantly. For $16 \mathrm{Mn}$, the area of fracture zone drops from $16.74 \mathrm{~mm}^{2}$ to $13.61 \mathrm{~mm}^{2}$ by $18.70 \%$; for 1045 , the area of fracture zone drops from $7.630 \mathrm{~mm}^{2}$ to $3.650 \mathrm{~mm}^{2}$ by $52.16 \%$; and for $16 \mathrm{Mn}$, the area of fracture zone drops from $1.25 \mathrm{~mm}^{2}$ to $1.15 \mathrm{~mm}^{2}$ by $0.08 \%$. The results prove that the optimal control method can reduce the section roughness and the area of the fracutre zone effectively for all the experimental materials in this experiment. That is, the optimal control method can effectively improve the section quality.

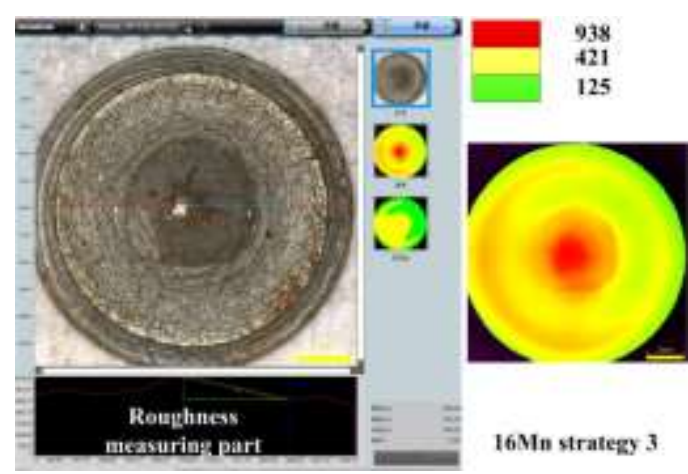

(a)

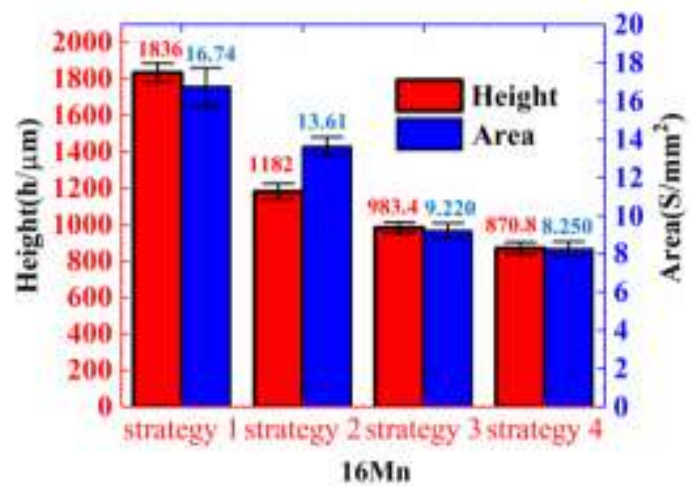

(b) 
361

362

363

364

365

366

367

368

369

370

371

372

373

374

375

376

377

378

379

380

381

382

383

384

385

386

387

388

389

390

391

392

393

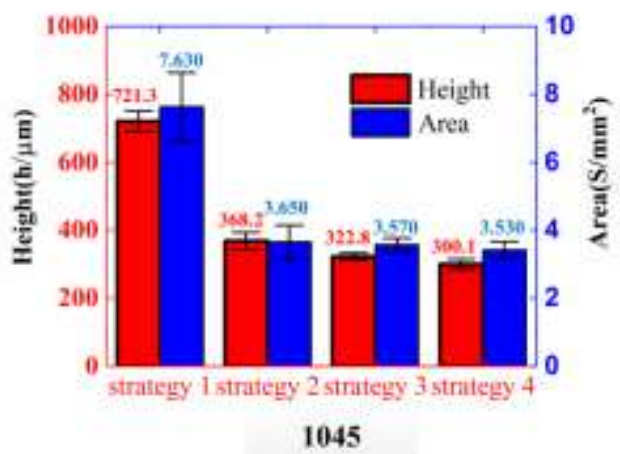

(c)

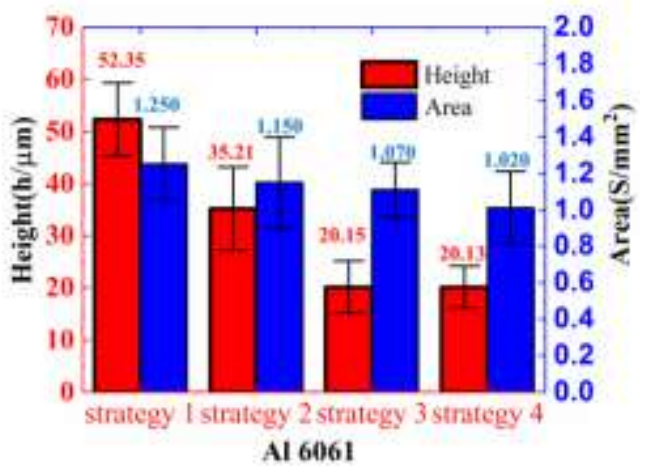

(d)

Figure 13. (a) The software interface of OLYMPUS DSX1000. (b) The height value and the area of fracture zone for $16 \mathrm{Mn}$ under four control strategies. (c) The height value and the area of fracture zone for 1045 under four control strategies. (d) The height value and the area of fracture zone for Al 6061 under four control strategies.

Further more, Figure 13(b), (c) and (d) show the influence of different loading frequencies on section quality. The height value and the area of the fracture zone reduce as the loading frequency reduces. For $16 \mathrm{Mn}$, when the loading frequency reduces from $8.33 \mathrm{~Hz}$ to $5 \mathrm{~Hz}$, the height value drops from $1182 \mu \mathrm{m}$ to $870.8 \mu \mathrm{m}$, and the area of fracture zone drops from $13.61 \mathrm{~mm}^{2}$ to $8.250 \mathrm{~mm}^{2}$. For 1045 , when the loading frequency reduces from $8.33 \mathrm{~Hz}$ to $5 \mathrm{~Hz}$, the height value drops from $368.2 \mu \mathrm{m}$ to $300.1 \mu \mathrm{m}$, and the area of the fracture zone drops from $3.650 \mathrm{~mm}^{2}$ to $3.530 \mathrm{~mm}^{2}$. For $\mathrm{Al} 6061$, when the loading frequency reduces from $8.33 \mathrm{~Hz}$ to $5 \mathrm{~Hz}$, the height value drops from $35.21 \mu \mathrm{m}$ to $20.13 \mu \mathrm{m}$, and the area of the fracture zone drops from $1.150 \mathrm{~mm}^{2}$ to $1.020 \mathrm{~mm}^{2}$. The results indicate the lower the loading frequency, the better the section quality. The influence trend of reducing loading frequency can be obtained by further comparison. For $16 \mathrm{Mn}$, when the loading frequency reduces from $8.33 \mathrm{~Hz}$ to $6.67 \mathrm{~Hz}$, the height value drops by $16.84 \%$, and the area of fracture zone drops by $32.26 \%$; with the loading frequency reducing from $6.67 \mathrm{~Hz}$ to $5 \mathrm{~Hz}$, the height value drops by $11.45 \%$, and the area of fracture zone drops by $10.52 \%$. For 1045 , with the loading frequency reducing from $8.33 \mathrm{~Hz}$ to $6.67 \mathrm{~Hz}$, the height value drops by $12.32 \%$, and the area of fracture zone drops by $0.022 \%$; with the loading frequency reducing from $6.67 \mathrm{~Hz}$ to $5 \mathrm{~Hz}$, the height value drops by $0.070 \%$, and the area of fracture zone drops by $0.011 \%$. For $\mathrm{Al} 6061$, with the loading frequency reduces from $8.33 \mathrm{~Hz}$ to $6.67 \mathrm{~Hz}$, the height value drops by $42.77 \%$, and the area of fracture zone drops by $0.070 \%$; with the loading frequency reduced from $6.67 \mathrm{~Hz}$ to $5 \mathrm{~Hz}$, the height value drops by $0.001 \%$, and the area of fracture zone drops by $0.047 \%$. It can be seen that as the frequency decreases, the efficiency of the cross-section quality improving decreases Considering the efficiency and the section quality, different control strategies can be adopted for different materials. Strategy 1, strategy 2 and strategy 3 are suitable for Al 6061, 1045 and $16 \mathrm{Mn}$, respectively.

\section{Conclusion}

In this study, a new LCFC system which includes three parts: LCFC machine, control system and monitoring system is established to find an optimized control method to ensure the cropping efficiency and improve section quality. Characteristics and mechanism of each stage during the LCFC are studied by using AE parameter, OM system and SEM, and a new optimal control 
method based on the AE technique is proposed. To compare the section quality before and after optimization, two evaluation indexs are presented and OLYMPUS DSX1000 is used to get 3D information of the section surface.The detailed conclusion is as follows.

(1) Ring-down counts is proved to be able to describe the whole LCFC process. In the crack initiaion stage, the ring-down counts close to 0 ; in the crack propagation stage, the ring-down counts increased evidently and reached a stable stage except Al 6061.For 16Mn, the values of ring-down counts remain stable between 7000 to 10000; for 1045, the value of ring-down counts remain stable between 7500 to 8500 . In the fracture stage, the ring-dwon counts drop to 0 rapidly.

(2) For $16 \mathrm{Mn}$ and 1045 , the peak of kurtosis concentrated in two areas. For $16 \mathrm{Mn}$, the first peak of kurtosis emerged from 0.6 1s, the second peak of kurtosis emerged from 9.8 10.8s. For 1045, the first peak of kurtosis emerged from 3.2 4.4s, the second peak of kurtosis emerged from 16.8 18.8s. There is no stable stage from crack propagation to fracture for $\mathrm{Al} 6061$. The peak kurtosis indicates a dramatic change in the state of the material which can be used to show the transition area between the different stages. Moreover, the kurtosis is not influenced by the threshold value of events. Hence, it is more suitable for monitoring the whole process of LCFC and as a critical parameter to optimize the control method than ring-down counts in a noisy factory environment.

(3) According to macroscopic images of the section, for $16 \mathrm{Mn}$ and 1045 three zones which related to crack initiation stage, crack propagation stage and fracture stage can be observed. For $\mathrm{Al}$ 6061, there is no obvious transition zone between the crack propagation stage and the fracture stage. The area of the fracture stage (zone III) is too small to find on the macroscopic section. By using SEM, it can be seen in the crack initiation stage, and fatigue loading leads to the formation of fatigue striations; in the crack propagation stage, the fatigue striations and the dimples can be observed simultaneously which indicates fatigue fracture and ductile fracture happen at the same time; In the fracture stage, lots of equiaxed dimples can be found. Tensile fracture is the main fracture form at this stage, and a large area of transient fracture zone is produced. By reducing the load frequency to reduce the area of the transient fracture zone is the key to improve section quality.

(4) Based on the characteristics of kurtosis, an optimal control method is come up. The metal bar is first applied a high frequency $(20 \mathrm{~Hz})$ cyclic loading. When the load time is over the $\mathrm{T}$ and the slope of kurtosis is bigger than $\mathrm{C}$, the computer give commands to a PLC to change the state of the serve motor from high frequency to low frequency until the metal bar fracture. Two control parameters, transient time $\mathrm{T}$ and the critical value of the slope of kurtosis $\mathrm{C}$ are determined. For $16 \mathrm{Mn}, 1045$ and $\mathrm{Al} 6061$, the $\mathrm{T}$ is $5 \mathrm{~s}, 10 \mathrm{~s}$, and $1 \mathrm{~s}$, respectively. For $16 \mathrm{Mn}$, 1045 and $\mathrm{Al}$ 6061, the $\mathrm{C}$ is 100, 300, and 0, respectively. Two parameters, $\mathrm{h}$ and $\mathrm{S}$, are used to evaluate the section quality. The results under four control strategies are compared by using OLYMPUS DSX1000 and indicate the optimal control methods can improve the section quality effectively.

(5) The influence trend of reducing loading frequency is investigated by further comparison. It can be seen as the frequency decreases, the efficiency of the section quality improving decreases. Considering the efficiency and the section quality, various control strategies can be adopted for different materials. Strategy 1 (high frequency is $20 \mathrm{~Hz}$, high frequency throught the whole process), strategy 2 (high frequency is $20 \mathrm{~Hz}$, low frequency is $8.33 \mathrm{~Hz}$ ) and strategy 

respectively.

440 


\section{Declarations}

442 Funding: This work is supported by the Aviation Joint Fund Project of National Natural Science 443 Foundation of China (Grant No. U1937203), State Key Laboratory for Mechanical Behavior of

444 Materials (Grant No. 1991DA105206)

445

Conflicts of interest/Competing interests: There is no conflict of interest in this manuscript.

447

448

Availability of data and material: Not applicable

449

450

Code availability: Not applicable

451

452

Authors' contributions: Not applicable

453

$454 \quad$ Nomenclature

455 LCFC

$456 \quad$ Low-cycle fatigue cropping

$457 \quad \mathrm{AE}$

458 Acoustic Emission

$459 \quad T$

460 Transient time, $\mathrm{s}$

461

462

The critical value of slope of kurtosis

463

$h$

464 The height between the highest point and the lowest point on the section

465

466

467

The area of the fracture zone 


\section{References}

[1]. Hua, C.J., et al., Investigation of a new-type precision cropping system with variable-frequency vibration. International Journal of Mechanical Sciences, 2006. 48(12): p. 1333-1340.

[2]. Dong, Y., et al., Laser-assisted cyclic chipless splitting for hard-to-cut thick wall tubes and fatigue fracture mechanism analysis. International Journal of Mechanical Sciences, 2020. 168: p. 105308.

[3]. Wang, Z., S. Zhao and Y. Yu, Study on the dynamic characteristics of the low-stress vibration cropping machine. Journal of Materials Processing Technology, 2007. 190(1): p. 89-95.

[4].Zhong, B., et al., Investigation on the influences of clearance and notch-sensitivity on a new type of metal-bar non-chip fine-cropping system. INTERNATIONAL JOURNAL OF MECHANICAL SCIENCES, 2013. 76: p. 144-151.

[5]. Zhang, L.J., et al., Investigation on the bar clamping position of a new type of precision cropping system with variable frequency vibration. International Journal of Machine Tools and Manufacture, 2007. 47(7): p. 1125-1131.

[6].Zhao, S.D., et al., Numerical study on heat stress prefabricating ideal crack at the bottom of V shaped notch in precision cropping. Journal of Materials Processing Technology, 2007. 187-188: p. 363-367.

[7]. Zhao, R., et al., Experimental investigation on new low cycle fatigue precision cropping process. PROCEEDINGS OF THE INSTITUTION OF MECHANICAL ENGINEERS PART C-JOURNAL OF MECHANICAL ENGINEERING SCIENCE, 2015. 229(8): p. 1470-1476.

[8]. Hua, C.J., et al., Investigation of a new-type precision cropping system with variable-frequency vibration. INTERNATIONAL JOURNAL OF MECHANICAL SCIENCES, 2006. 48(12): p. 1333-1340.

[9]. Carolan, T.A., et al., Acoustic emission monitoring of tool wear during the face milling of steels and aluminium alloys using a fibre optic sensor .1. energy analysis. PROCEEDINGS OF THE INSTITUTION OF MECHANICAL ENGINEERS PART B-JOURNAL OF ENGINEERING MANUFACTURE, 1997. 211(4): p. 299-309.

[10].FANG, D. and A. BERKOVITS, FATIGUE DESIGN-MODEL BASED ON DAMAGE MECHANISMS REVEALED BY ACOUSTIC-EMISSION MEASUREMENTS. JOURNAL OF ENGINEERING MATERIALS AND TECHNOLOGY-TRANSACTIONS OF THE ASME, 1995. 117(2): p. 200-208.

[11]. Roberts, T.M. and M. Talebzadeh, Acoustic emission monitoring of fatigue crack propagation. JOURNAL OF CONSTRUCTIONAL STEEL RESEARCH, 2003. 59(6): p. 695-712.

[12]. Elforjani, M. and D. Mba, Detecting natural crack initiation and growth in slow speed shafts with the Acoustic Emission technology. Engineering Failure Analysis, 2009. 16(7): p. 2121-2129.

[13]. Han, Z., et al., Acoustic emission during fatigue crack propagation in a micro-alloyed steel and welds. MATERIALS SCIENCE AND ENGINEERING A-STRUCTURAL MATERIALS PROPERTIES MICROSTRUCTURE AND PROCESSING, 2011. 528(25-26): p. 7751-7756.

[14]. Yu, J., et al., Acoustic emission detection of fatigue damage in cruciform welded joints. Journal of Constructional Steel Research, 2013. 86: p. 85-91.

[15]. Aggelis, D.G., E.Z. Kordatos and T.E. Matikas, Acoustic emission for fatigue damage characterization in metal plates. Mechanics Research Communications, 2011. 38(2): p. 106-110.

[16]. Chai, M., et al., Assessment of fatigue crack growth in 316LN stainless steel based on acoustic emission entropy. INTERNATIONAL JOURNAL OF FATIGUE, 2018. 109: p. 145-156. 
[17]. Li, J., et al., Acoustic emission characteristics in eccentric rotary cropping process of stainless steel tube. INTERNATIONAL JOURNAL OF ADVANCED MANUFACTURING TECHNOLOGY, $514 \quad 2017.92(1-4):$ p. 777-788.

515 [18]. Ren, Y., et al., The investigation of low-cycle fatigue crack propagation of $16 \mathrm{Mn}$ eccentric bar 516 based on the acoustic emission technique. Proceedings of the Institution of Mechanical Engineers, Part B: Journal of Engineering Manufacture, 2020.

518 [19]. Carpinteri, A., C. Ronchei and S. Vantadori, Stress intensity factors and fatigue growth of surface 519 cracks in notched shells and round bars: two decades of research work. FATIGUE \& FRACTURE OF ENGINEERING MATERIALS \& STRUCTURES, 2013. 36(11SI): p. 1164-1177. Emission Signal from Defective Bearings. Journal of Failure Analysis and Prevention, 2014. 14(3): p. 363-71.

524 


\section{Figures}

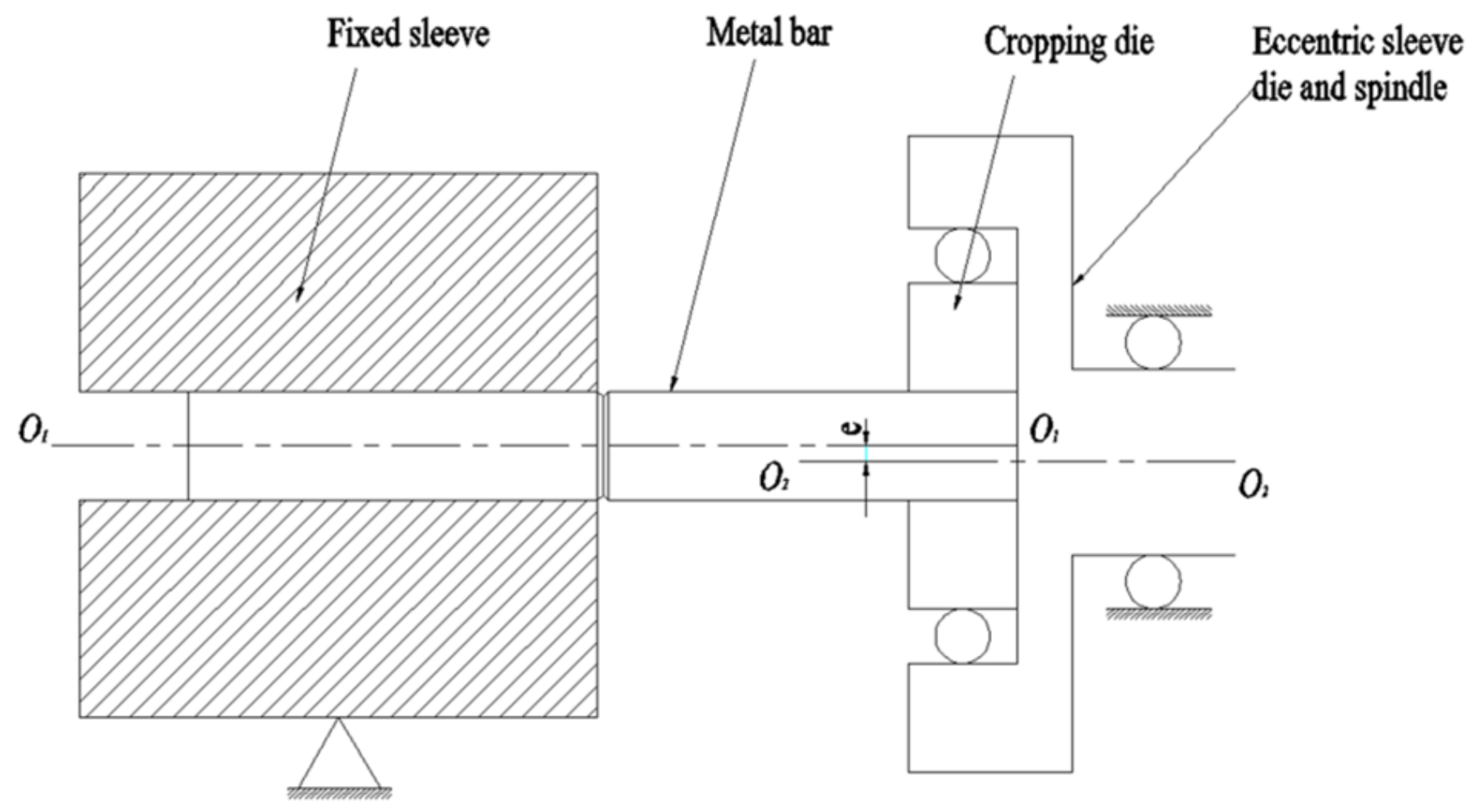

Figure 1

The schematic diagram of the working principle of LCFC.

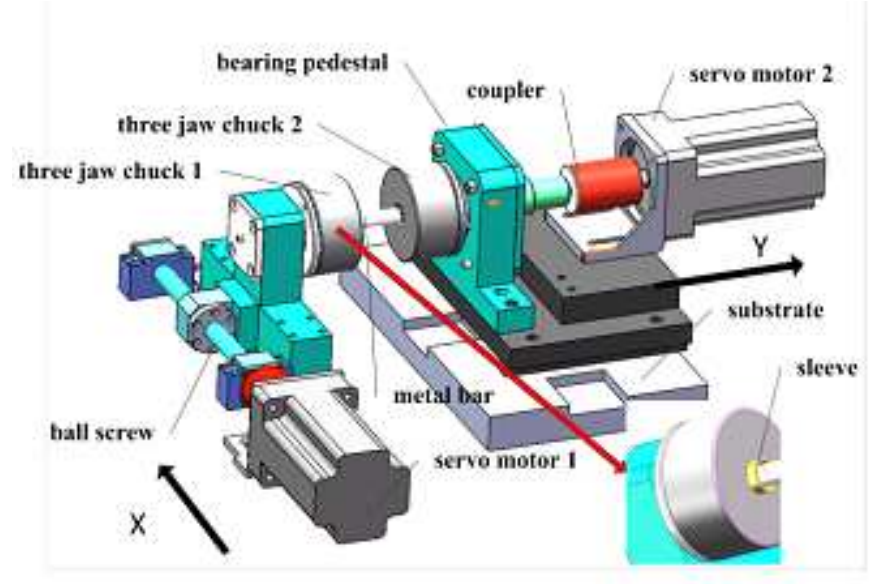

(a)

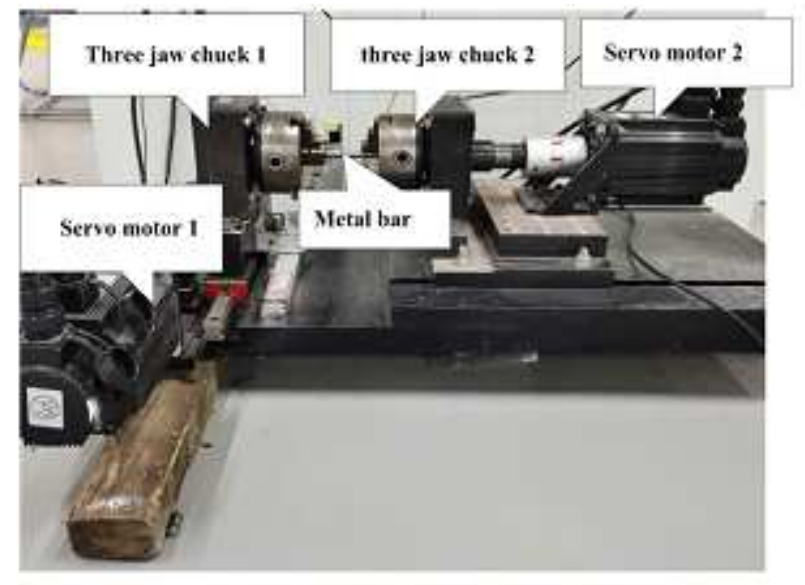

(b)

\section{Figure 2}

The new types of LCFC machine. (a) Structural schematic diagram (b) Experimental device 

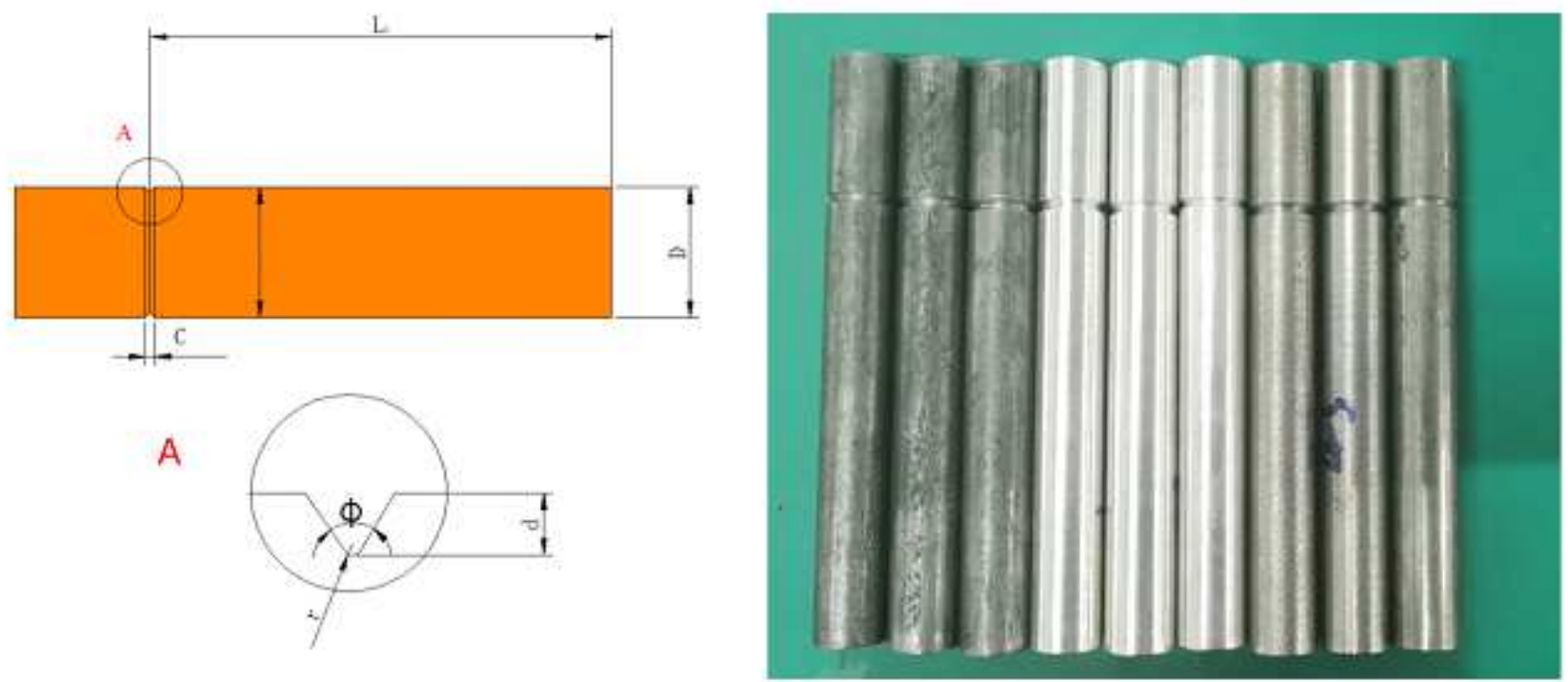

(a)

(b)

\section{Figure 3}

The geometric paramters and the images of the metal bar.(a) The diagram of geometrical structure (b) The images of three types metal bar:from left to right are 16Mn, Al 6061and 1045.

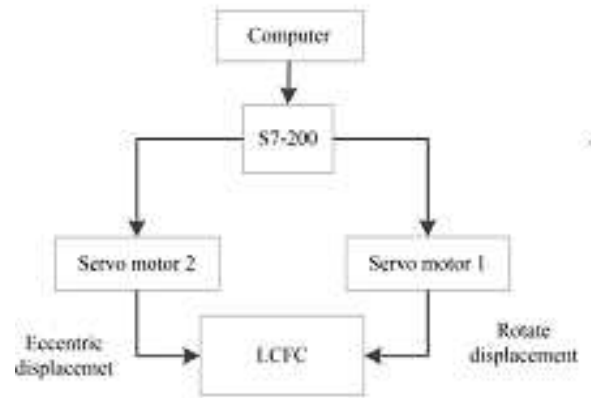

(a)

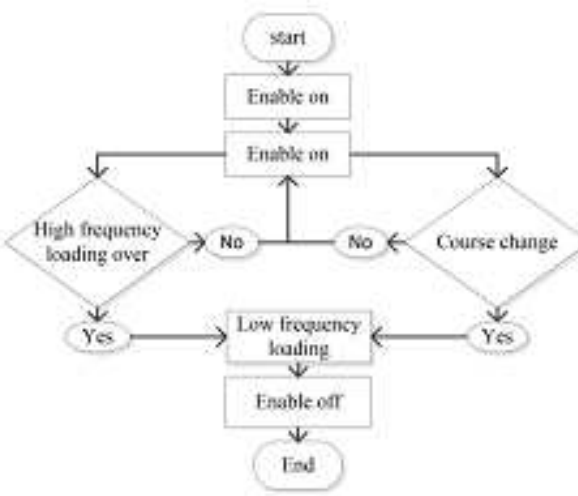

(b)

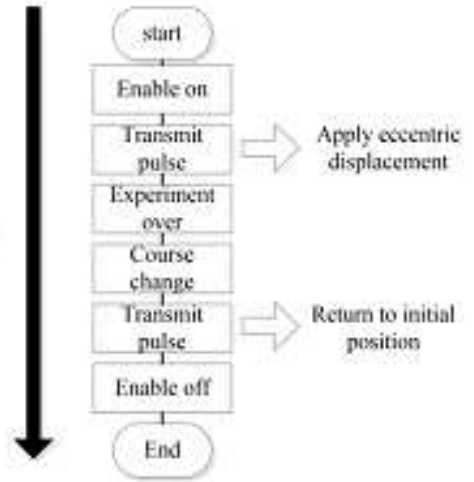

(c)

Figure 4

Schematic of the control system. (a) Two servo motors are controlled by s7-200 PLC. (b) Flow chart of rotation control program. (c) Flow chart of eccentric displacement control program. 

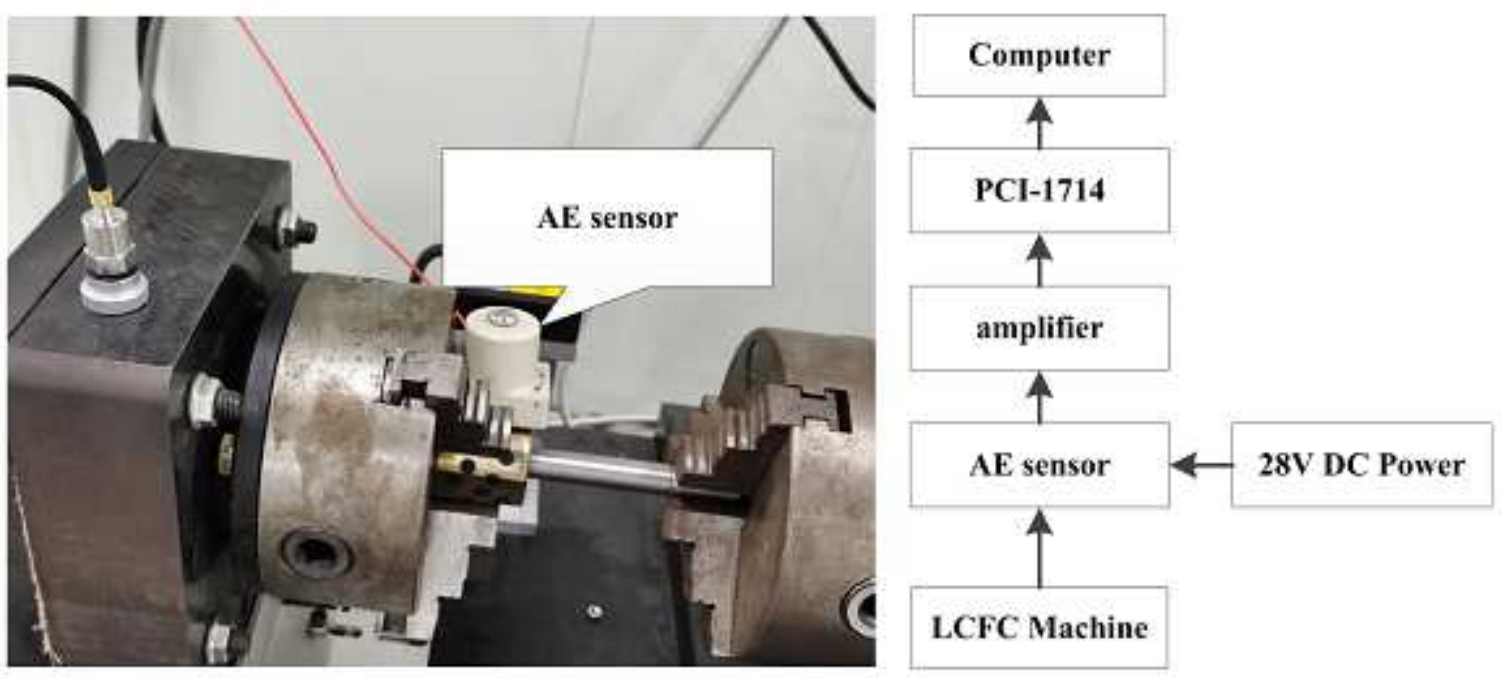

Figure 5

The diagram of the monitoring system. 


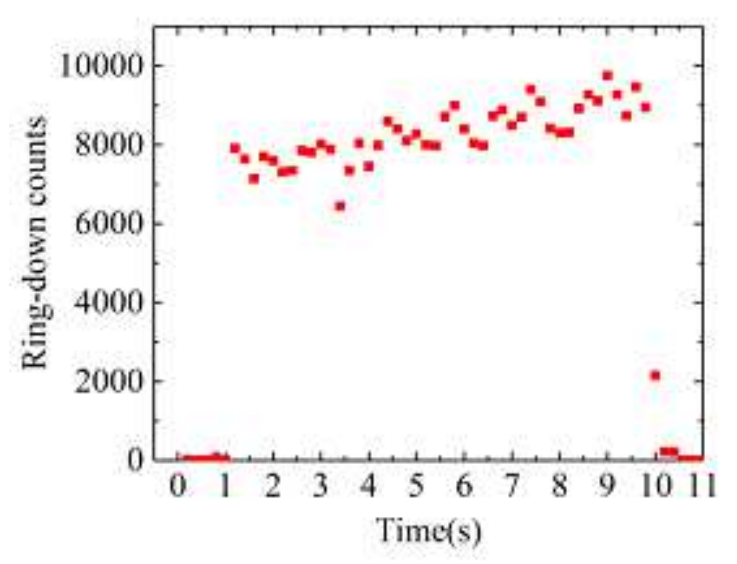

(a)

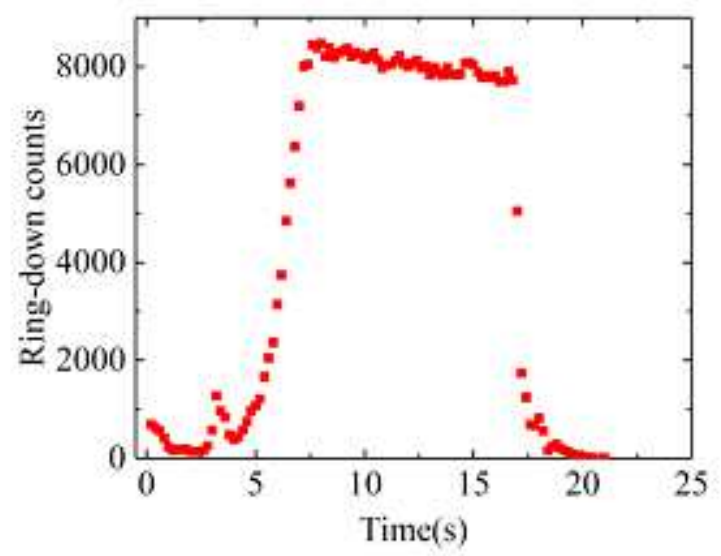

(c)

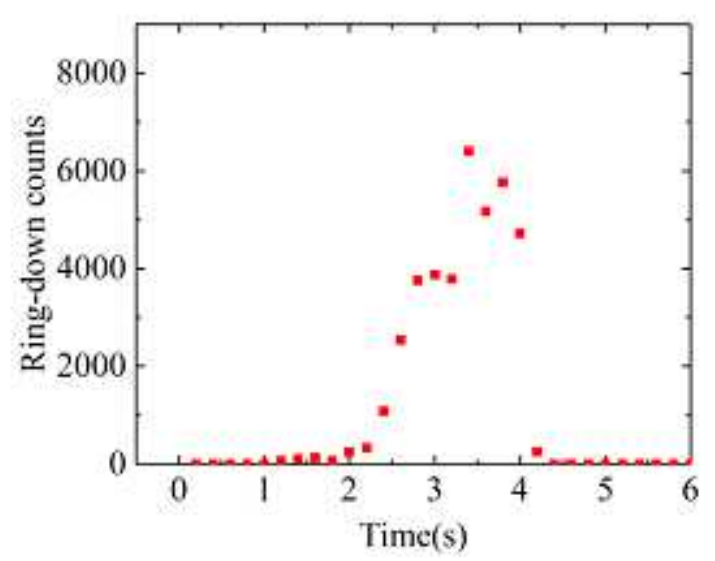

(e)

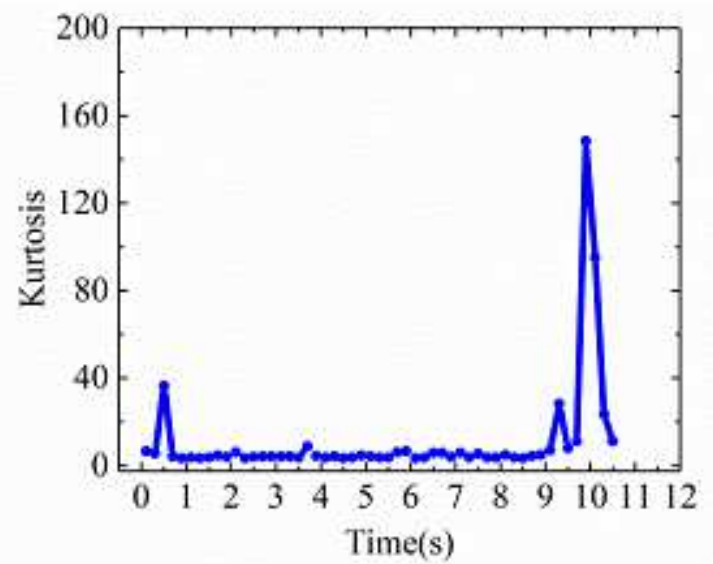

(b)

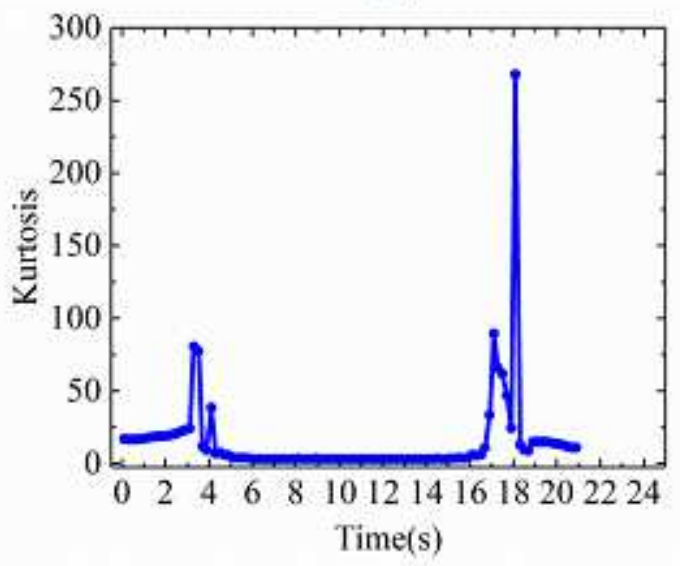

(d)

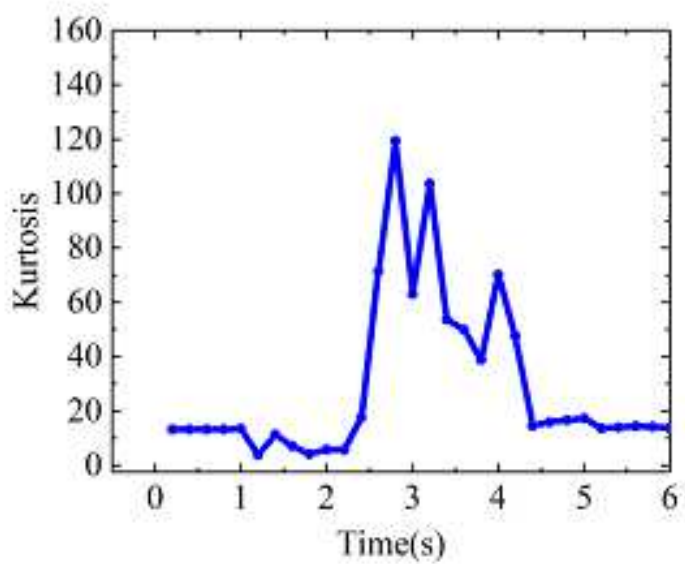

(f)

\section{Figure 6}

Ring-down counts vs. time (a, c, e) and kurtosis vs. time (b, d, f) with 16Mn specimens (a b), 1045 specimens (c, d) and Al 6061 (e, f). 


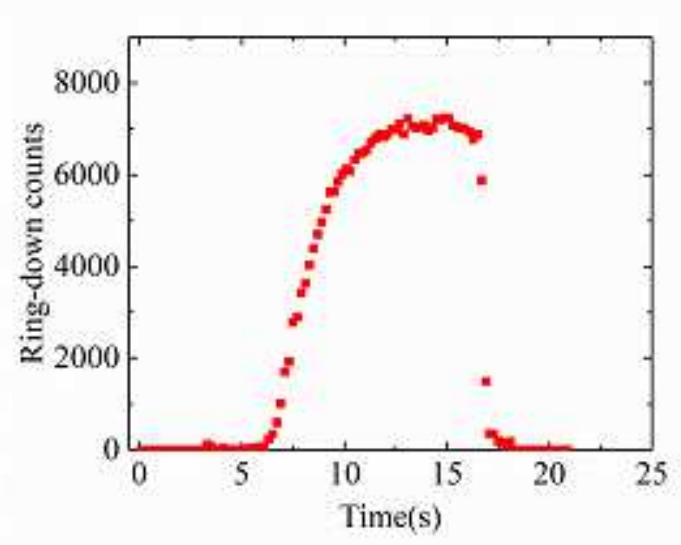

(a)

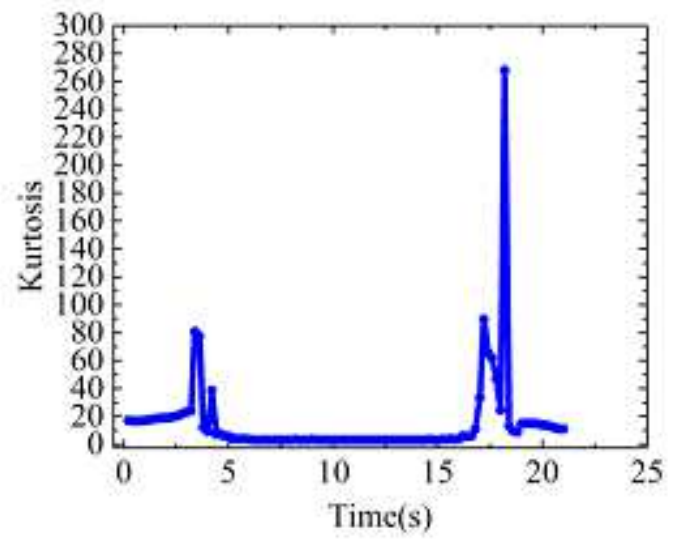

(b)

\section{Figure 7}

Ring-down counts vs. time (a) and kurtosis vs. time (b) with 1045 specimens when the threshold value of peak event is 0.3 .

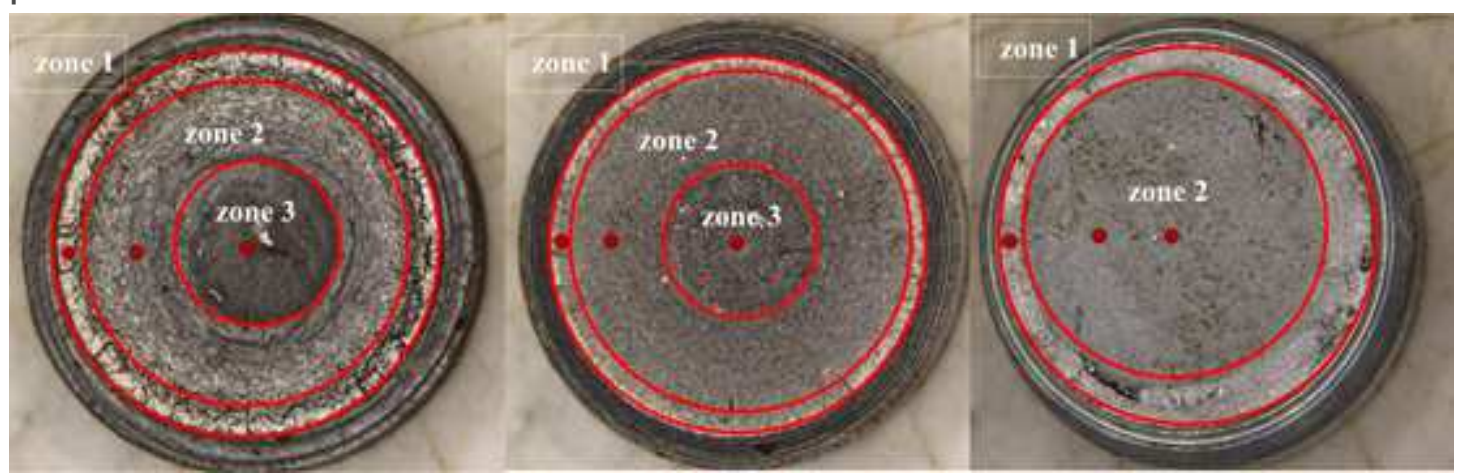

\section{Figure 8}

The macroscopic cross-sections of metal bars. (a) 16Mn, (b) 1045, and (c) Al 6061. 


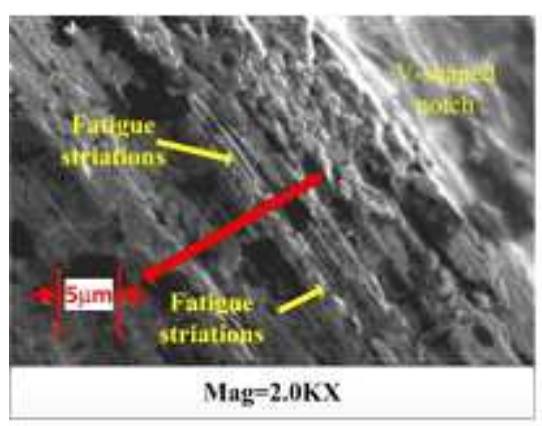

(a)

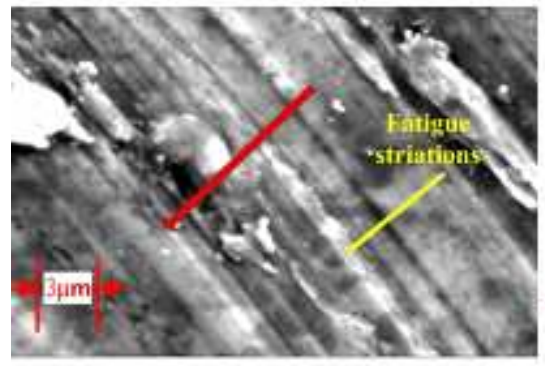

Mag=3.0KX

(d)

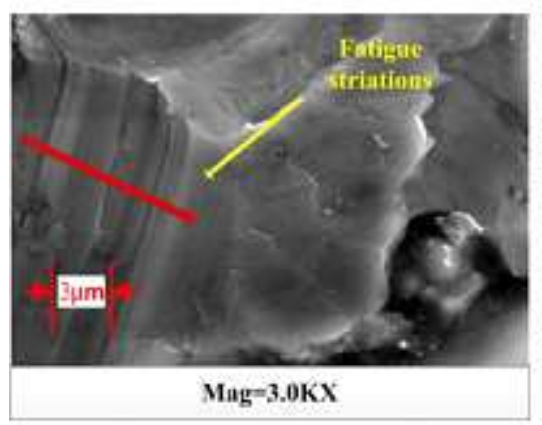

(g)

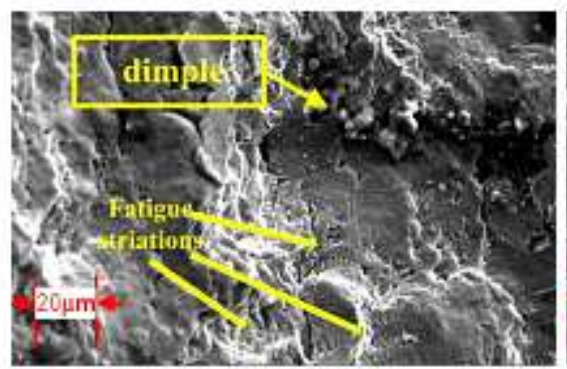

$\mathrm{Mag}=500 \mathrm{X}$

(b)

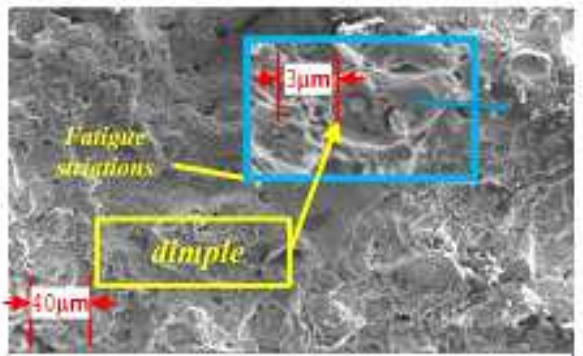

Mag $=200 X$

(e)

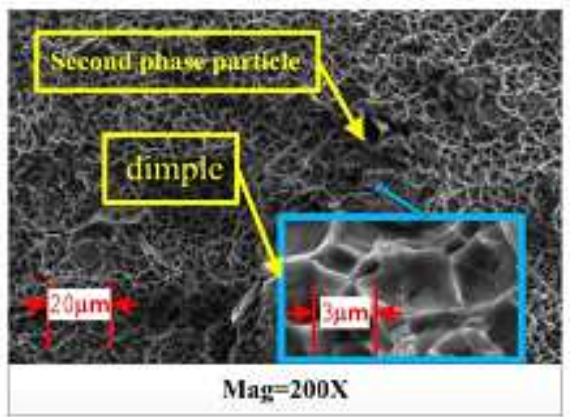

(h)

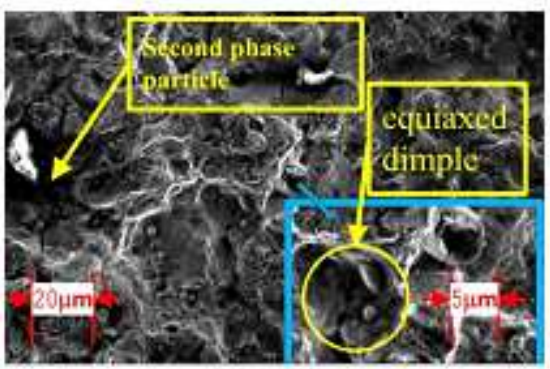

$M a g=500 X$

(c)

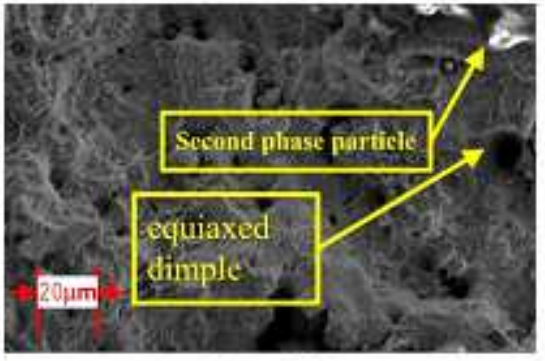

Mag-500X

(f)

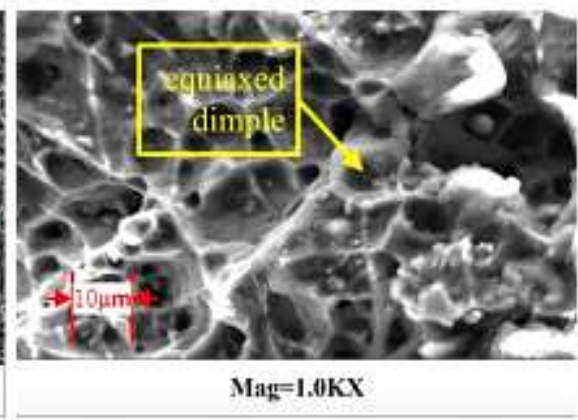

(i)

Figure 9

Different stages of fatigue fracture surface of three types of materials (a) crack initiation area of $16 \mathrm{Mn}$ (b) crack propagation area of $16 \mathrm{Mn}$ (c) fracture area of $16 \mathrm{Mn}$ (d) crack initiation area of 1045 (e) crack propagation area of 1045 (f) fracture area of $16 \mathrm{Mn}(\mathrm{g})$ crack initiation area of Al 6061 (h) crack propagation area of Al 6061 (i) fracture area of Al 6061 


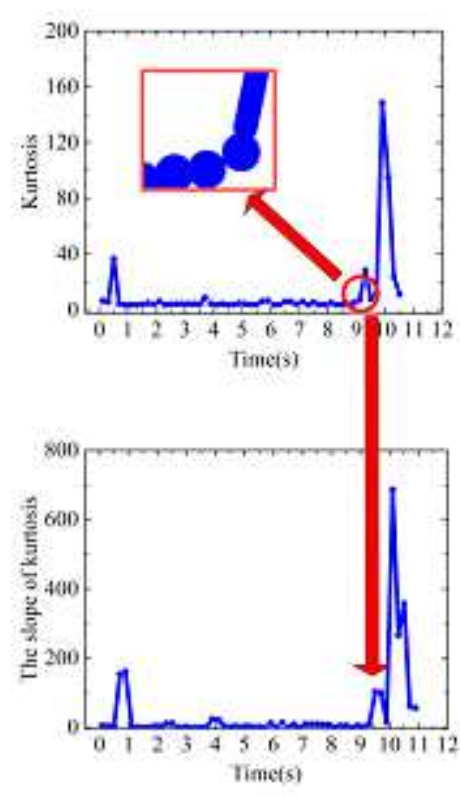

(a)

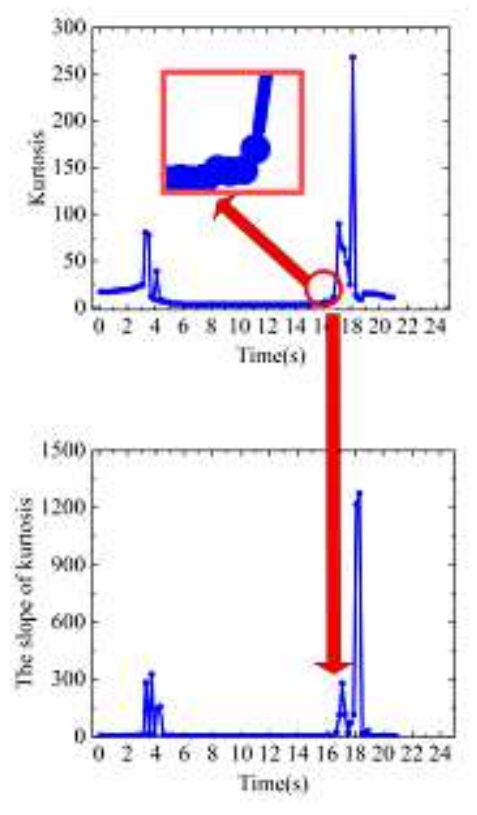

(b)

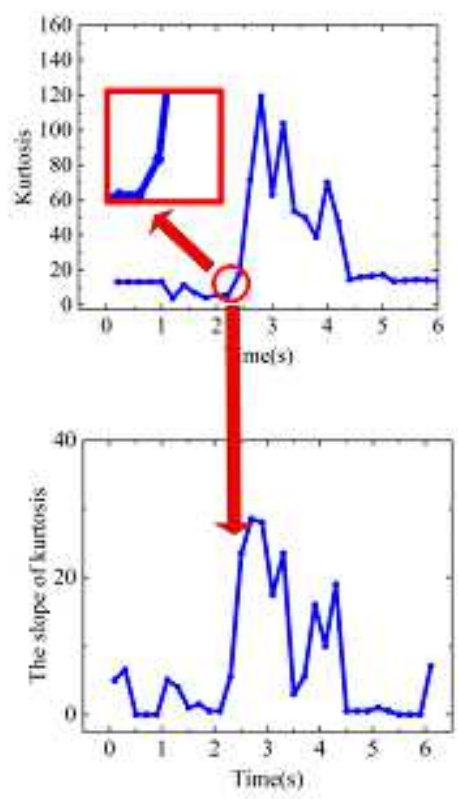

(c)

Figure 10

The rise edge of kurtosis and the slope of kurtosis of metal bars (a) 16Mn (b) 1045 (c) Al 6061

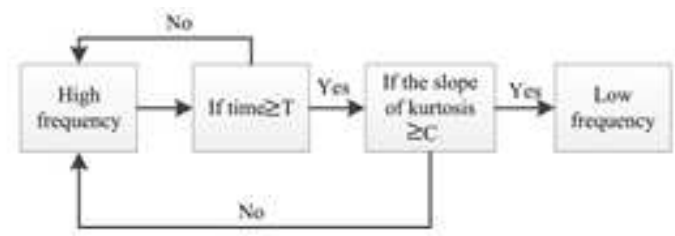

Figure 11

The logic of optimize control method

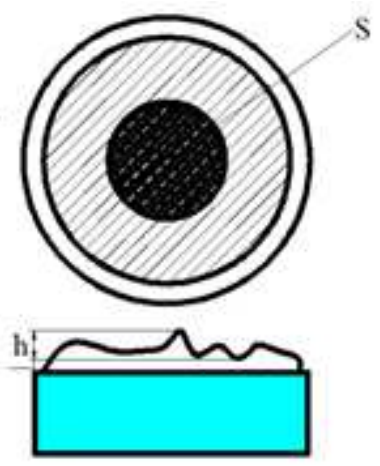

Figure 12

The diagram of two section quality evaluation indexes. 


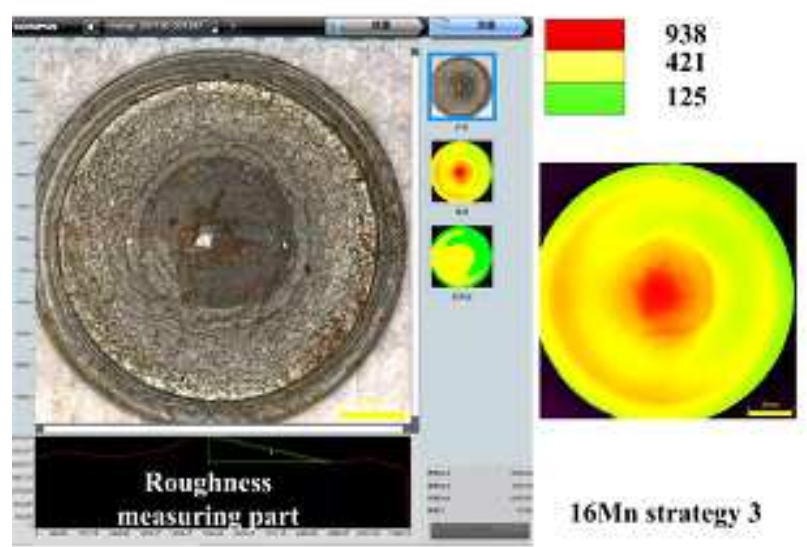

(a)

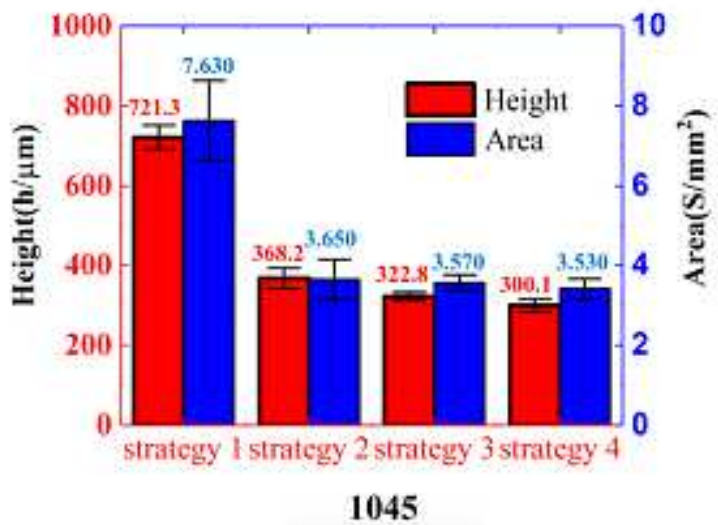

(c)

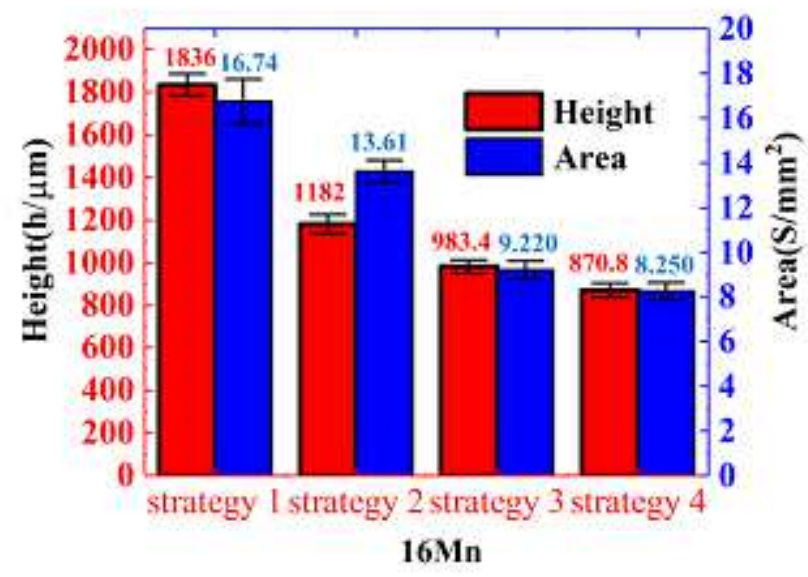

(b)

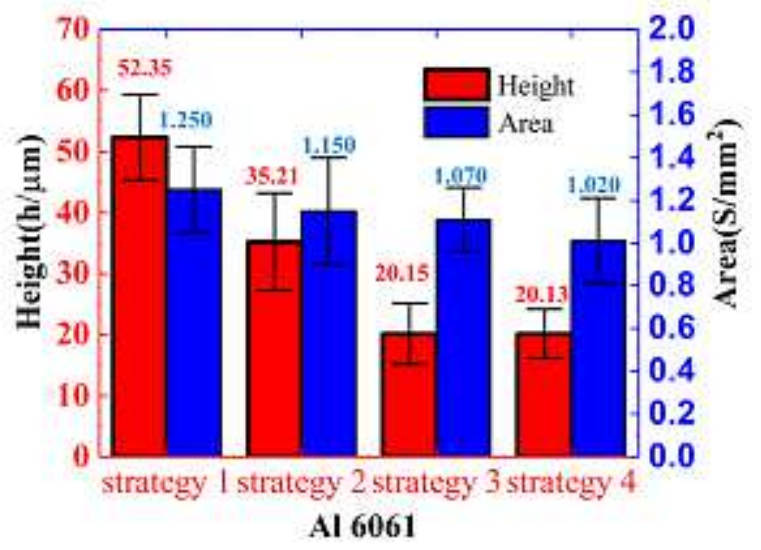

(d)

\section{Figure 13}

(a) The software interface of OLYMPUS DSX1000. (b) The height value and the area of fracture zone for $16 \mathrm{Mn}$ under four control strategies. (c) The height value and the area of fracture zone for 1045 under four control strategies. (d) The height value and the area of fracture zone for Al 6061 under four control strategies. 